\title{
Improved detection of gene-microbe interactions in the mouse skin microbiota using high-resolution QTL mapping of 165 rRNA transcripts
}

\author{
Meriem Belheouane ${ }^{1,2}$, Yask Gupta ${ }^{3}$, Sven Künzel ${ }^{1}$, Saleh Ibrahim ${ }^{3+}$ and John F. Baines ${ }^{1,2^{*+}}$
}

\begin{abstract}
Background: Recent studies highlight the utility of quantitative trait locus (QTL) mapping for determining the contribution of host genetics to interindividual variation in the microbiota. We previously demonstrated that similar to the gut microbiota, abundances of bacterial taxa in the skin are significantly influenced by host genetic variation. In this study, we analyzed the skin microbiota of mice from the 15th generation of an advanced intercross line using a novel approach of extending bacterial trait mapping to both the 165 rRNA gene copy (DNA) and transcript (RNA) levels, which reflect relative bacterial cell number and activity, respectively.

Results: Remarkably, the combination of highly recombined individuals and 53,203 informative SNPs allowed the identification of genomic intervals as small as $<0.1$ megabases containing single genes. Furthermore, the inclusion of $16 \mathrm{~S}$ rRNA transcript-level mapping dramatically increased the number of significant associations detected, with five versus 21 significant SNP-bacterial trait associations based on DNA-compared to RNA-level profiling, respectively. Importantly, the genomic intervals identified contain many genes involved in skin inflammation and cancer and are further supported by the bacterial traits they influence, which in some cases have known genotoxic or probiotic capabilities.

Conclusions: These results indicate that profiling based on the relative activity levels of bacterial community members greatly enhances the capability of detecting interactions between the host and its associated microbes. Finally, the identification of several genes involved in skin cancer suggests that similar to colon carcinogenesis, the resident microbiota may play a role in skin cancer susceptibility and its potential prevention and/or treatment.
\end{abstract}

Keywords: QTL mapping, Skin microbiota, 16S rRNA transcript, Skin cancer

\section{Background}

Mammals host a wide range of complex and diverse microbial communities in association with their barrier organs, which contribute to critical aspects of host biology. Accordingly, many studies of the resident microbiota in the past decade provided primary surveys in a variety of different contexts (e.g., organ, disease state, genotype,

\footnotetext{
* Correspondence: baines@evolbio.mpg.de

${ }^{\dagger}$ Equal contributors

${ }^{1}$ Max Planck Institute for Evolutionary Biology, August-Thienemann-Str. 2, 24306 Plön, Germany

${ }^{2}$ Institute for Experimental Medicine, Christian-Albrechts-University of Kiel, Arnold-Heller-Str. 3, 24105 Kiel, Germany

Full list of author information is available at the end of the article
}

development, geography) [1-5]. A salient feature of these studies is the revealing of substantial diversity between individuals. Thus, a thorough understanding of the fundamental factors that govern the assembly and stability of bacterial communities is of critical importance. Broadly speaking, studies addressing these questions identify the environment, diet, and host genetics as important contributors to interindividual variation in host-associated communities [6-8].

The influence of host genetics on bacterial community structure has been addressed by a number of different approaches in human and mouse models, such as twin studies $[9,10]$, comparison of mouse inbred strains [11, 
12], quantitative trait locus (QTL) analysis [13, 14], and more recently first genome-wide association studies [15-19]. These studies provide valuable insights into the role of host genetics in shaping the structure of the bacterial communities, although are largely limited to gut communities.

The skin offers numerous niches for microbes and accordingly harbors complex bacterial communities [20], which differ between distinct body sites and individuals. However, individuals display greater intrapersonal than interpersonal similarity within a specific skin habitat over time [21,22], suggesting that in addition to other principles governing community stability, host genetics may be a contributing factor to these observed patterns. In a recent study, we addressed whether host genetic variation contributes to variation in the skin microbiota in mice by employing a QTL mapping approach to the fourth generation of an advanced intercross line (AIL) [23]. This revealed a total of 13 regions of the mouse genome significantly associated to skin bacterial traits, although the large size of the defined genomic regions (from 9 to 33 megabases) did not easily allow for more detailed characterization of the individual genes involved.

In this study, we aimed to improve the mapping resolution of QTLs for skin microbial abundances by using the 15th generation of the previously used AIL [23], which we generated through the continuous random intercrossing of individuals, and by increasing the marker density to 53,203 informative SNPs. Furthermore, we introduced a novel means of microbial phenotyping in a QTL context by performing $16 \mathrm{~S}$ ribosomal RNA (rRNA) profiling at both the gene copy (DNA) and transcript (RNA) levels, which reflect relative bacterial cell number and activity, respectively. Our analysis reveals numerous genomic regions associated with skin microbial abundances, in several cases containing single immune- and/or skin cancer-related genes, whereby $16 \mathrm{~S}$ rRNA transcript-level profiling was considerably more effective in terms of the number of associations identified. This suggests that bacterial activity levels may provide deeper insight into mechanisms of host-microbe interactions than DNA-level profiling alone.

\section{Results}

\section{Skin microbiota composition in the AIL mapping population}

In order to fine-map genomic regions influencing bacterial taxon abundances in the skin, we analyzed a total of 270 mice from the 15th generation (hereafter $G_{15}$ ) of the same AIL from which we previously analyzed the 4th generation $\left(\mathrm{G}_{4}\right)$ [23]. An important factor to consider when analyzing the $G_{15}$ mice is that the AIL was transferred from an animal facility at the University of
Rostock to a new animal facility at the University of Lübeck, shortly after the analysis of the $G_{4}$ mice was conducted. Thus, prior to QTL mapping, we conducted a thorough ecological analysis of the $G_{15}$ mice in order to re-evaluate the bacterial taxa present and to aid the interpretation of mapping results. Furthermore, given that the skin harbors comparatively low biomass communities and is in constant contact with the environment, we reasoned that bacterial 16S rRNA transcripts may in some cases better reflect true resident skin bacteria interacting with their host. Thus, we performed 16S rRNA gene amplicon (V1-V2 hypervariable regions) sequencing on the Illumina MiSeq platform using both bacterial genomic DNA and RNA reverse transcribed into complementary DNA (cDNA) as template. In total, we analyzed nearly two million sequences after quality filtering and processing, with a normalized coverage of 3500 sequences per sample for each of the DNA- and RNA-based datasets, which we refer to as the "standing" and "active" communities, respectively.

First, we analyzed community composition at the phylum and genus levels (Fig. 1). Overall, the mean relative abundances of the major phyla and genera vary largely between the standing and active datasets (Table 1). Proteobacteria is the most abundant phylum in both standing and active datasets (46 and 44\%, respectively) and does not significantly differ between them. Bacteroidetes and Firmicutes, on the other hand, display significant contrasting patterns between the standing and active communities, with Bacteroidetes being more abundant at the DNA compared to the RNA level (19 versus 13\%, respectively) and Firmicutes being almost twofold more abundant at the RNA compared to the DNA level (29 versus 16\%, respectively). Actinobacteria and Cyanobacteria make up a smaller proportion of the standing communities (5.3 and 4.7\%, respectively) and are further significantly reduced in the active communities (3 and $2.5 \%$, respectively). These relative patterns at the RNA compared to the DNA level are also largely reflected by the respective most abundant genera belonging to each of these phyla (Fig. 1c, d; Table 1).

To further examine the correspondence of abundances at the DNA and RNA levels for a single taxon, we investigated their correlations. Among the most abundant taxa, we observe overall moderate to poor correlations; Proteobacteria, Bacteroidetes, unclassified Lachnospiraceae, unclassified Clostridiales, and Staphylococcus abundances show a moderate, positive, and significant correlation, whereas Firmicutes abundances correlate poorly between the standing and active datasets (Fig. 2a, b). This indicates that the presence and activity of taxa vary distinctively across individuals and bacterial groups.

Next, we compared the overall community composition between the $G_{15}$ and $G_{4}$ populations. Although 

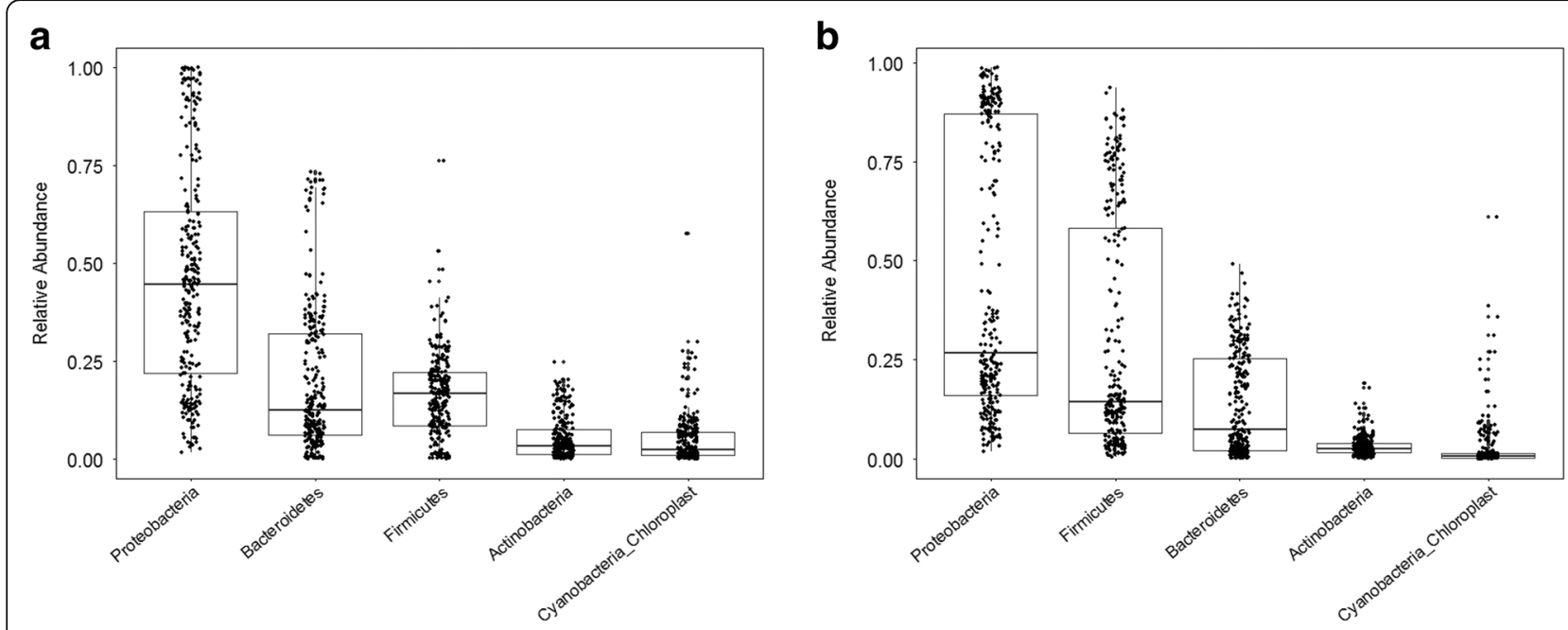

C

d
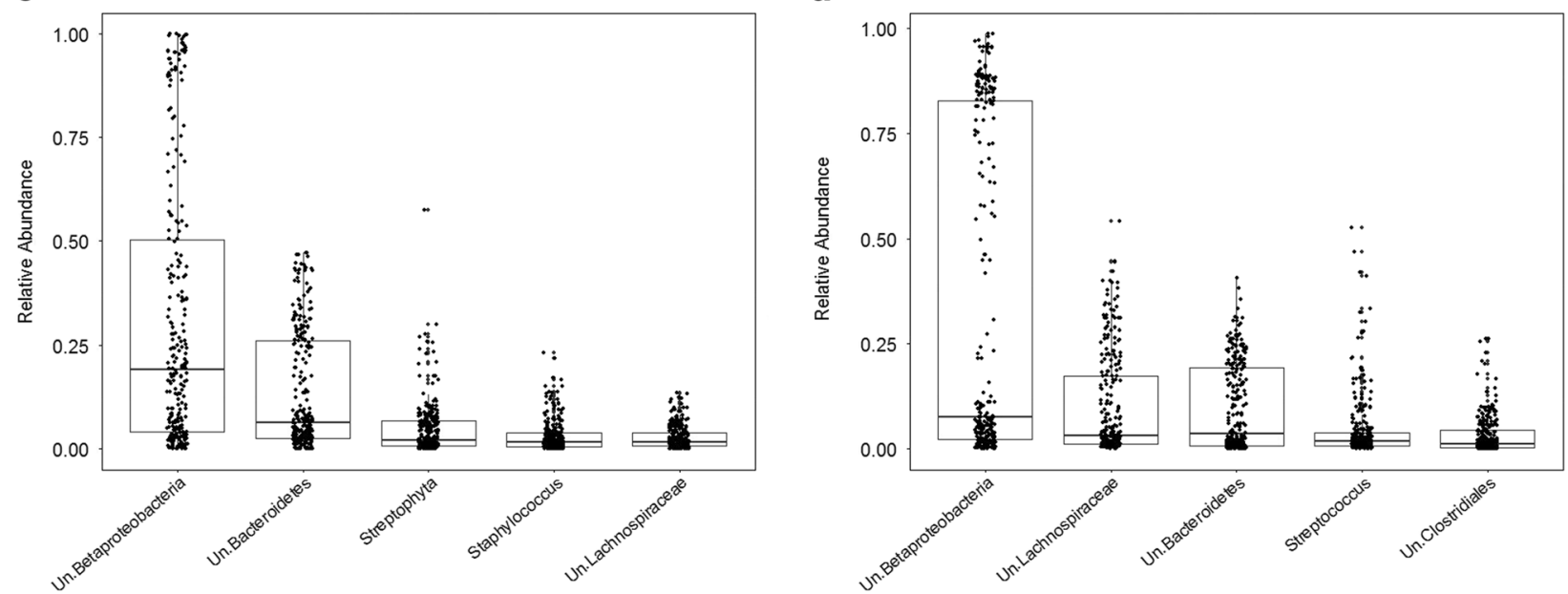

Fig. 1 Relative abundances of phyla and genera. The five most abundant phyla and genera are shown. a Major phyla in standing (DNA-based) communities. b Major phyla in active (RNA-based) communities. c Major genera in standing (DNA-based) communities. $\mathbf{d}$ Major genera in active (RNA-based) communities. Un unclassified

Table 1 Mean relative abundances of major taxa between standing and active communities in the $\mathrm{G}_{15}$ population

\begin{tabular}{lll}
\hline Rank & Taxon & Paired Wilcoxon test \\
\hline Phylum & Proteobacteria & 0.43 \\
Phylum & Bacteroidetes & $1.68 \times 10^{-12}$ \\
Phylum & Firmicutes & $3.97 \times 10^{-11}$ \\
Phylum & Actinobacteria & $2.24 \times 10^{-5}$ \\
Phylum & Cyanobacteria_Chloroplast & $3.97 \times 10^{-11}$ \\
Genus & Streptophyta & $6.65 \times 10^{-10}$ \\
Genus & Staphylococcus & $6.04 \times 10^{-10}$ \\
Genus & Un.Lachnospiraceae & $2.2 \times 10^{-15}$ \\
Genus & Streptococcus & $6.65 \times 10^{-10}$ \\
Genus & Un.Clostridiales & $1.5 \times 10^{-5}$ \\
\hline
\end{tabular}

Significant $p$ values $(\leq 0.05)$ after Benjamini-Hochberg [27] correction for multiple testing are indicated in italics

Un unclassified there is a large degree of overlap in terms of the major taxa present, significant differences between these two mouse cohorts are already apparent among phylum-level abundances, whereby the former $\mathrm{G}_{4}$ cohort is dominated by Firmicutes in contrast to the $G_{15}$, which is dominated by Proteobacteria (Fig. 3a-c). Systematic communitylevel differences are also clearly revealed by beta diversity analyses (Additional file 1), whereby the standing and active communities of the $G_{15}$ display much more similarity to each other than either does to the standing communities of the $G_{4}$, despite the differences in abundance between the DNA- and RNA-based profiling outlined above.

\section{Patterns of variation among Core Measurable Microbiota taxa}

For further analysis, we defined a "Core Measurable Microbiota" (CMM) [13] (see "Methods") for the $G_{15}$ 

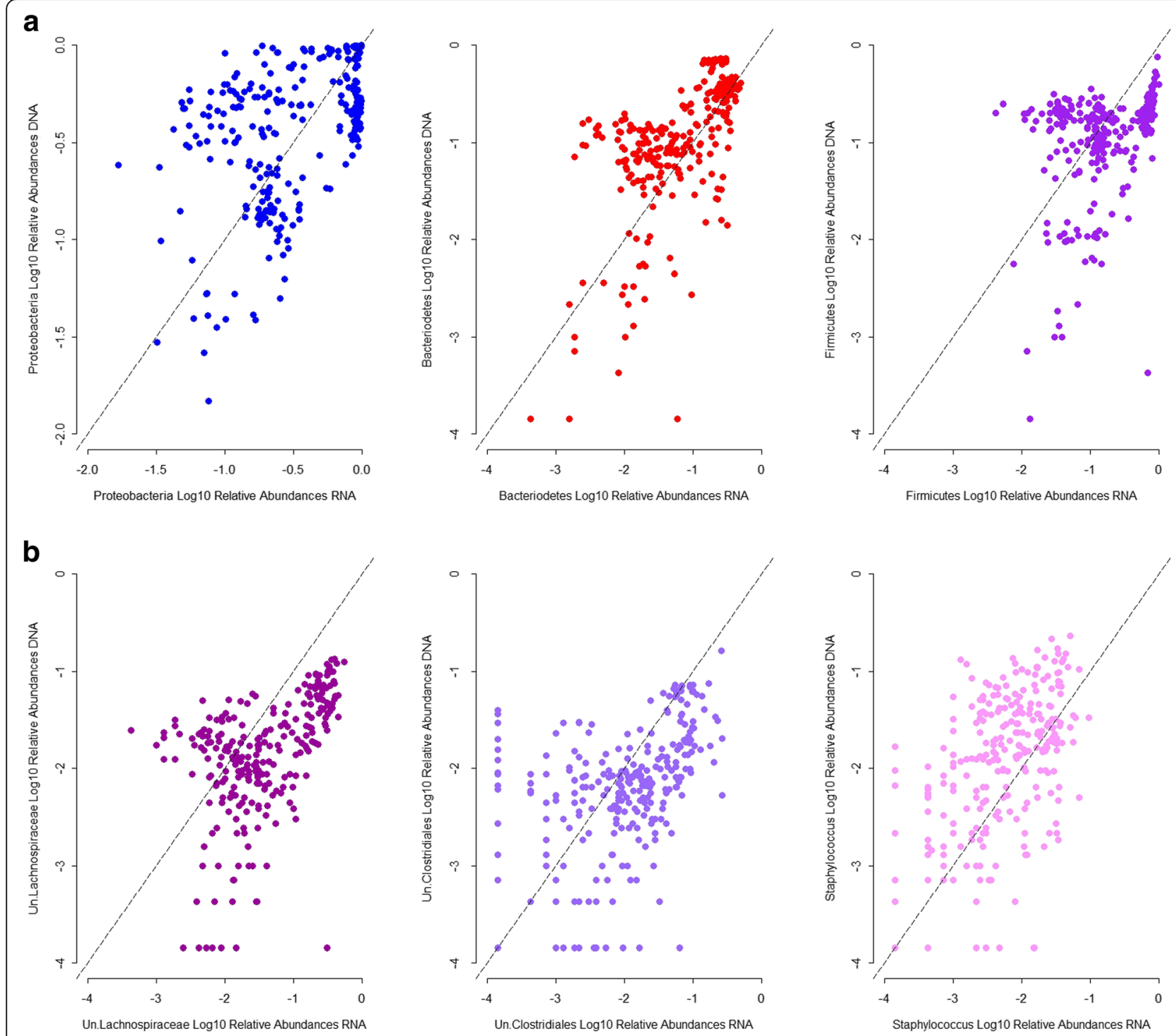

Fig. 2 Correlation between standing and active relative abundances for representative taxa. a Phyla. b Genera. Spearman's correlation: Proteobacteria: $r=0.42, p=4.19 \times 10^{-13}$; Bacteroidetes: $r=0.66, p=3.3 \times 10^{-16}$; Firmicutes: $r=0.39, p=2.72 \times 10^{-11}$; Un.Lachnospiraceae: $r=0.56, p$ $=3.3 \times 10^{-16}$; Un.Clostridiales: $r=0.50, p=3.3 \times 10^{-16}$; Staphylococcus: $r=0.48, p=3.3 \times 10^{-16}$. Un unclassified. $p$ values are adjusted following Benjamini and Hochberg method [27]

population, which in total contains 92 taxa from the genus to the phylum level and 44 species-level operational taxonomic units (OTUs). The CMM traits represent a small fraction (9 and $0.2 \%$, for CMM taxa and OTUs, respectively) of all detected taxa, but their cumulative abundances represent more than 90 and $60 \%$ of taxon and OTU abundances, respectively, within the entire standing and active datasets. Due to the known technical challenges of metagenomic analysis of low microbial biomass samples such as the skin [24, 25], we evaluated the possible influence of contamination during experimental procedures on our ability to reliably measure the CMM and other traits included in the QTL analysis (CMM traits plus those previously significant in the $G_{4}$ population, see below) using "SourceTracker" [26]. This analysis reveals minimal estimates of contamination for the mapped genera and species-level OTUs (97\% similarity threshold), whereby estimates for the active communities are in each case lower (mean \pm standard deviation, genus: DNA $5.2 \pm 3.4 \%$, RNA $3.8 \pm 3.5 \%$; OTU: DNA $3.2 \pm 2.2 \%$, RNA $2.5 \pm 2.5 \%$ ).

To assess the degree of interindividual variation within each CMM trait, we calculated summary statistics of the relative abundances in the standing and active datasets (Additional files 2, 3, 4, and 5). The relative abundances of the CMMs vary greatly across individuals. For 

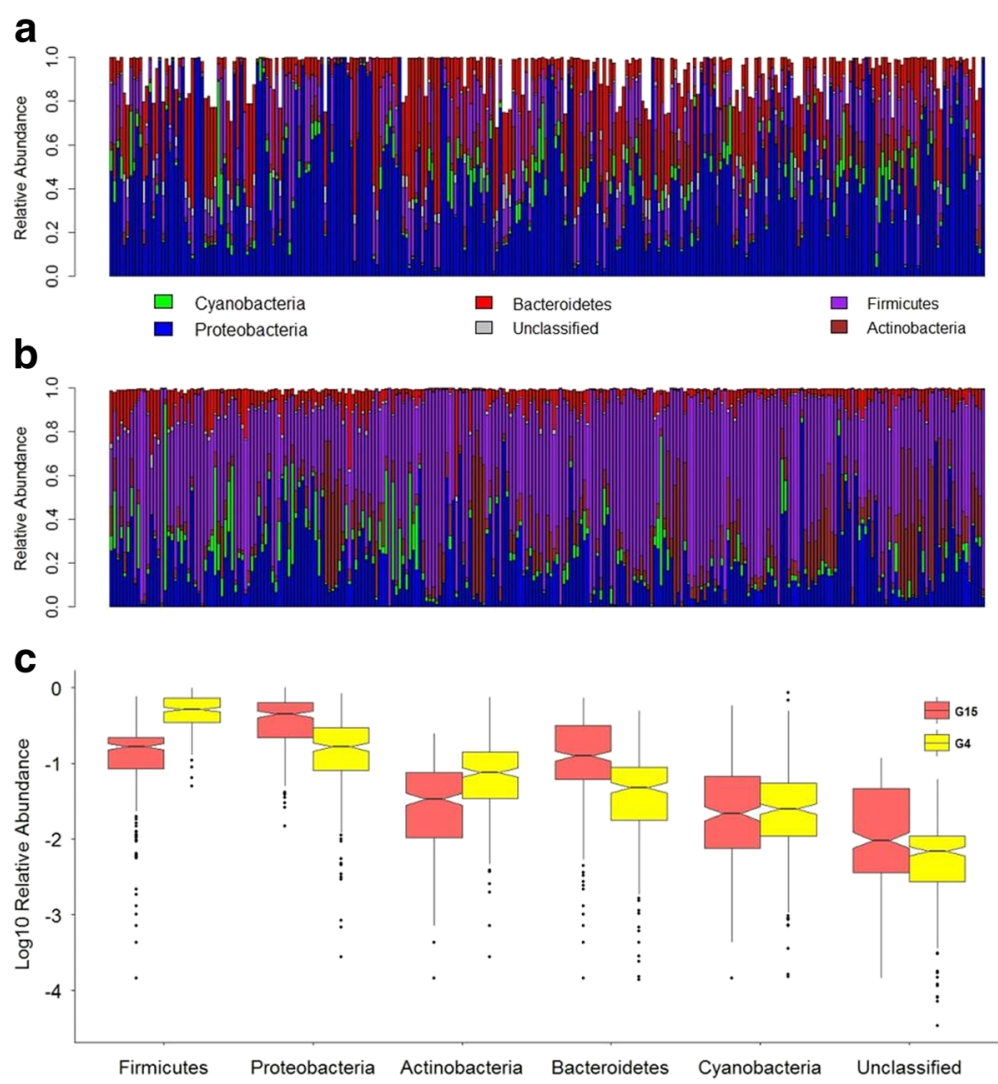

Fig. 3 Comparison of skin microbiota composition between $G_{4}$ and $G_{15}$ populations. a Bar plot of phylum abundances in the $G_{15}$ population. $\mathbf{b}$ Bar plot of phylum abundances in the $G_{4}$ population. $\mathbf{c}$ Boxplots of $\log _{10}$-transformed mean relative abundances of major phyla in populations $G_{4}$ and $\mathrm{G}_{15}$. ANOVA: Firmicutes, $p=2.2 \times 10^{-16}$; Proteobacetria, $p=2.2 \times 10^{-16}$

example, in the standing communities, unclassified Betaproteobacteria ranges from 1.5 to $100 \%$, while Staphylococcus_OTU16 varies from 1.3 to $17.3 \%$. Examples in the active communities include Campylobacter, which ranges from 2.1 to $31.9 \%$, and Acinetobacter_OTU18, which ranges from 0.7 to $44.9 \%$. As expected, the most abundant CMMs harbor the highest dispersion across individuals, whereas the least abundant ones display tighter dispersion.

To measure the influence of the cage environment, gender, and age on the interindividual variation in the CMMs, we built a mixed effects model for each CMM trait using the $\log _{10}$-transformed relative abundance as the response variable, gender and age as fixed explanatory variables, and cage as a random term, separately for the standing and active communities. Accordingly, we quantified the fractions of total variance explained by each of these factors (Additional files 6, 7, 8, and 9), which varies considerably across CMM traits and between the standing and active datasets. For example, in the standing communities, only $0.52 \%$ of the total variance in Enterobacteriaceae abundance is explained by cage, whereas cage explains $32.98 \%$ of the total variance in Deltaproteobacteria abundance, and similar patterns are observed for the active communities. Within individual CMM traits, some display large correspondence between the standing and active communities (e.g., cage explains 21.14 and $17.20 \%$ of variation in Peptostreptococcaceae abundance in DNA- and RNA-based data, respectively), whereas others do not (e.g., cage explains 12.05 compared to $0 \%$ of the variation in Alistipes abundance in DNA- compared to RNA-based data, respectively). On average, the fraction of total variance explained by cage is higher in the standing compared to active communities (DNA: genus to phylum taxa $12.91 \%$, species $12.67 \%$; RNA: genus to phylum taxa $10.58 \%$, species $9.42 \%)$. Similar to the cage environment, the variance explained by gender and age also fluctuates substantially across CMM traits and their relative patterns in the standing and active communities. However, the fraction of total variance explained by gender and age combined is higher in the active compared to standing communities (DNA: genus to phylum taxa 12.44\%, species $12.59 \%$; RNA: genus to phylum taxa $25.26 \%$, species $16.61 \%)$. Importantly, after accounting for cage, gender, and age effects, the remaining residual variation still 
comprises the greatest proportion of total variance for nearly all CMM traits. The residuals for all mapped traits are provided in Additional file 10.

\section{QTL mapping of the skin microbiota in the $\mathrm{G}_{15}$}

To identify regions of the host genome influencing variation in skin microbial traits in the $\mathrm{G}_{15}$ population, we performed linkage mapping (see "Methods") on the 136 CMM traits described in addition to alpha diversity. Further, in an attempt to potentially replicate previously identified QTLs, we additionally included those CMM traits that showed significant associations with the host genome in the $G_{4}$ and are present in the $G_{15}$, but do not meet the criteria to be defined as part of the CMM in the $\mathrm{G}_{15}$. In total, we identified 13 significant $(p \leq 0.05)$ and 12 suggestive $(p \leq 0.1)$ QTLs among the standing and active community traits (Fig. 4, Table 2). Notably, QTL sizes span narrow confidence intervals ranging from 5 to $0.08 \mathrm{Mb}$, which in some cases contain single genes, and the phenotypic variance explained by individual peak SNPs averaged across all traits accounts for approximately $9 \%$ of the total variance. Five QTLs are defined for the standing communities, two of which have pleiotropic effects. For example, the genomic region on chromosome 9, ranging from 77 to $80 \mathrm{Mb}$, is associated with variation in both Deltaproteobacteria and Bacteroidetes_OTU23. In comparison, 21 QTLs are present among the active communities, none of which overlap with those identified for the standing communities. Two of the active QTLs are for Prevotellaceae, whereas the same region is identified at the genus and species levels for Ralstonia (Table 2). Further, we identified a single QTL influencing genus-level alpha diversity (Chao1) in the active communities.

To further evaluate the reliability of bacterial traits as measured by NGS-based methods, we independently analyzed three bacterial traits for which QTLs were detected (Betaproteobacteria, Epsilonproteobacteria, and Streptococcus) by performing qPCR measurements on a random subset of 80 mice using group-specific primers.

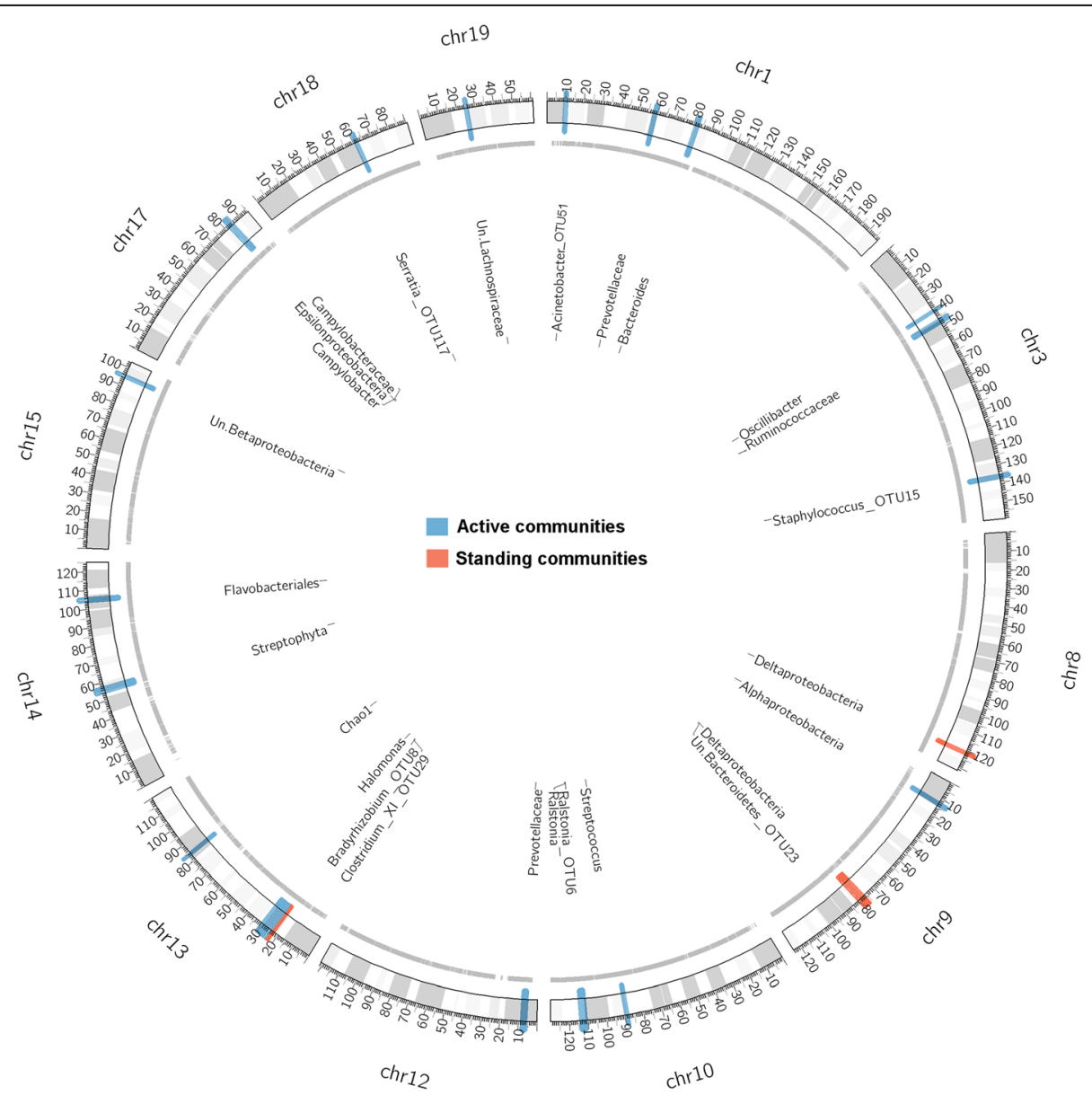

Fig. 4 QTL mapping of the standing and active microbiota in the $\mathrm{G}_{15}$ population. Only chromosomes with identified QTLs are shown. Black lines on the chromosomes denote SNPs used in the mapping, and each colored region denotes a QTL defined on either the standing (DNA) or active (RNA) communities 


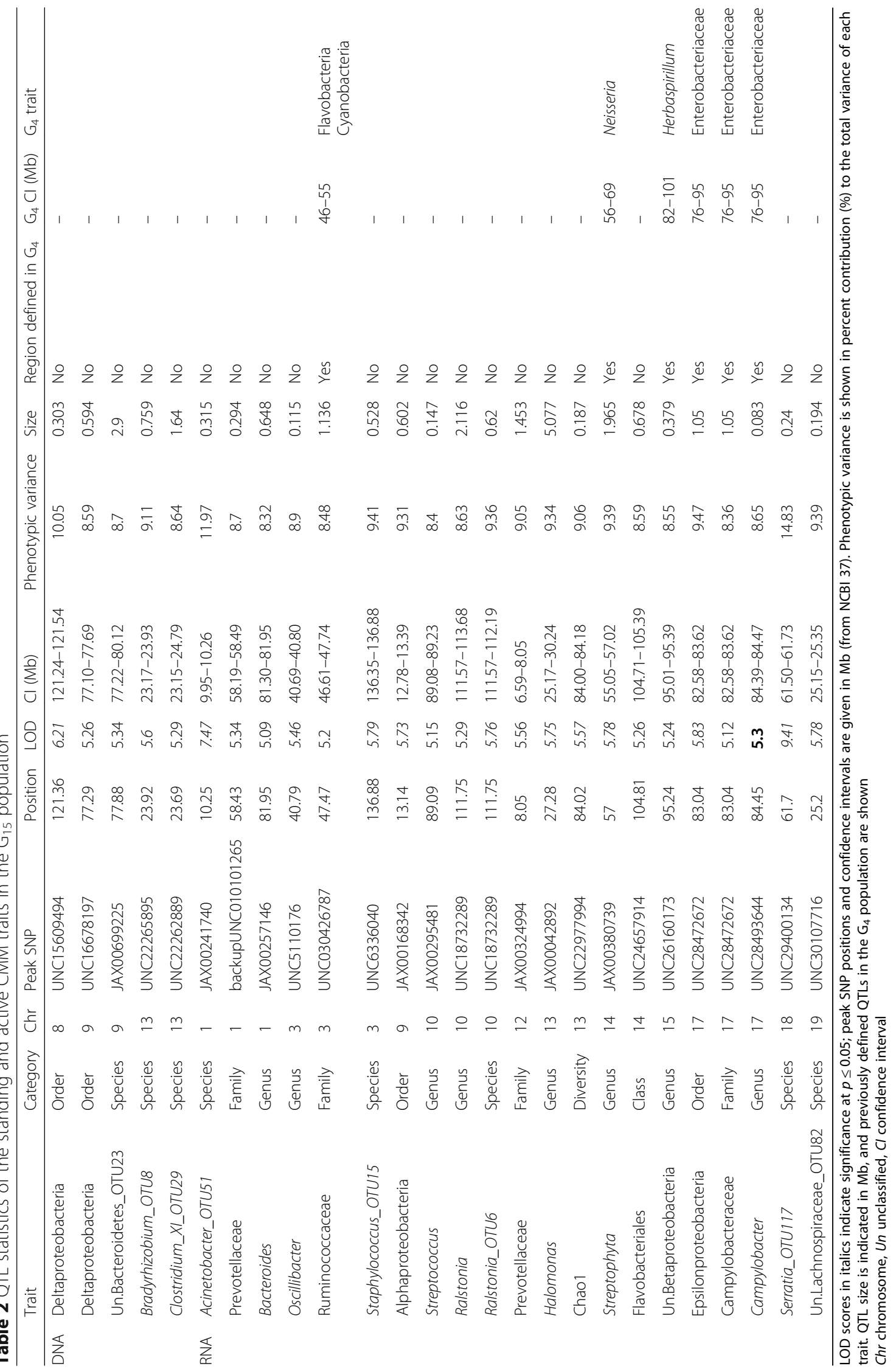


The relative abundances assessed by sequence profiles and $\mathrm{qPCR}$ estimates display significant positive correlations for all three traits (Spearman's correlation: Epsilonproteobacteria: $\quad r=0.40, \quad p=0.0003$; unclassified Betaproteobacteria: $r=0.25, p=0.02$; Streptococcus: $r=$ $0.36, p=0.0012 ; p$ values corrected according to Benjamini-Hochberg [27]), thus supporting the reliability of our bacterial phenotyping methods.

To determine whether we replicate previously detected QTLs in the $G_{4}$ population, we compared the identified genomic regions in the $G_{15}$ to our previous study [23]. The most promising trait is Neisseria, which was associated to chromosome 14 (confidence interval 56 to $69 \mathrm{Mb}$ ) in the $G_{4}$ population. In $G_{15}$, the confidence interval ranges from 60.55 to $60.98 \mathrm{Mb}$, the LOD score of the peak SNP is 9.01, and the percent explained variance is $14.24 \%$, although it is not significant at our determined genome-wide thresholds (Additional file 11). We did, however, discover four genomic regions contained within regions previously detected in the $\mathrm{G}_{4}$ that are significantly associated with four CMM traits in the $G_{15}$ population (Table 2), although the bacterial taxa are not the same.

In addition, we compared the intervals detected in our $\mathrm{G}_{15}$ analysis to published human GWAS and mouse QTL studies. While none of the loci previously associated with skin microbial traits in humans [16, 28] were contained within our $G_{15}$ intervals, we detect some overlap with QTL studies of the gut microbiota in mice $[3,13]$. These include the QTL on chromosome 10 (111.57-113.68 Mb) for the genus Ralstonia and corresponding OTUs, which overlaps with a pleiotropic genomic region from Benson et al. [13] on chromosome 10 associated with Coriobacteriaceae (106-122 Mb) and Lactococcus and Streptococcaceae (100-111 Mb). Additionally, our QTL on chromosome $12(6.59-8.05 \mathrm{Mb})$ for Prevotellaceae overlaps with a QTL on chromosome $12(-26 \mathrm{Mb})$ for Ruminococcaceae identified by Benson et al. [13]. Finally, our QTL located on chromosome 15 (95.01-95.39 Mb) for unclassified Betaproteobacteria overlaps with a QTL for Rikenellaceae on chromosome 15 (92.73-97.39 Mb) identified by McKnite et al. [3].

\section{Analysis of candidate regions}

Due to the narrow confidence intervals identified in the $\mathrm{G}_{15}$, we were able to identify many promising candidate genes. In Table 3, we list the genes related to the immune response and/or other skin biological processes contained within our confidence intervals whose functions are supported by experimental evidence. The functions of the potential candidate genes are further summarized in Additional file 12 and can largely be

Table 3 List of potential candidate genes located in the defined confidence intervals

\begin{tabular}{|c|c|c|c|c|c|}
\hline & Trait & Category & $\mathrm{Chr}$ & Immune-related genes & Genes related to skin biological processes \\
\hline \multirow[t]{5}{*}{ DNA } & Deltaproteobacteria & Order & 8 & - & Cdh13 \\
\hline & Deltaproteobacteria & Order & 9 & Gclc & - \\
\hline & Un.Bacteroidetes_OTU23 & Species & 9 & Gclc, Fbxo9, Ick, Gsta4, Eefia1 & Gsta4, Gsta1, Gsta2, Cd109, Ddx43,Col12a1 \\
\hline & Bradyrhizobium_OTU8 & Species & 13 & Trim38, Hfe, Btn1a1, Btn2a2 & - \\
\hline & Clostridium_XI_OTU29 & Species & 13 & Trim38, Hfe, Btn1a1, Btn2a2, Cmah & Cmah \\
\hline \multirow[t]{12}{*}{ RNA } & Acinetobacter_OTU51 & Species & 1 & Cops5 & Arfgef1 \\
\hline & Prevotellaceae & Family & 1 & CIK1 & - \\
\hline & Staphylococcus_OTU15 & Species & 3 & Ppp3ca & - \\
\hline & Streptococcus & Genus & 10 & Scyl2 & Scyl2 \\
\hline & Prevotellaceae & Family & 12 & - & Apob \\
\hline & Halomonas & Genus & 13 & Sox4 & Prl, Sox4, Cdkal, E2f3 \\
\hline & Streptophyta & Genus & 14 & $\begin{array}{l}\text { Mmp14, Psmb11, Cebpe, I125, Psme1, Psme2, Irf9, } \\
\text { Rnf31, Mdp1, Rabggta, Ripk3, Cma1, Mcpt1, Mcpt4, } \\
\text { Mcpt8, Ctsg, Gzmd, Gzmn, Gzmf, Gzmc, Gmzb, } \\
\text { Homez }\end{array}$ & $\begin{array}{l}\text { Mmp 14, Ltb4r2, Ltb4r1, Psme1, Mcpt1, Mcpt4, } \\
\text { Psme2, Prmt5, Slc7a8, Cmtm5, Pck2, Rec8, } \\
\text { Nedd8, Tgm1, Dhrs1, Ctsg, Gzme, Gmzb, } \\
\text { Atp12a, Tinf2 }\end{array}$ \\
\hline & Flavobacteriales & Order & 14 & - & Pou4f1 \\
\hline & Un.Betaproteobacteria & Genus & 15 & - & Nell2 \\
\hline & $\begin{array}{l}\text { Epsilonproteobacteria, } \\
\text { Campylobacteraceae }\end{array}$ & $\begin{array}{l}\text { Order, } \\
\text { family }\end{array}$ & 17 & - & $P k d c c$ \\
\hline & Serratia_OTU117 & Species & 18 & - & Ppargcib, Csnk1al \\
\hline & Un.Lachnospiraceae_OTU82 & Species & 19 & Dock8 & Dock8 \\
\hline
\end{tabular}

Only genes whose functions are experimentally demonstrated to be related to immune response and/or to other skin biological processes are reported. Genes in bold indicate the presence of the peak SNP

Chr chromosome, Un unclassified 
divided into five diverse groups: immune response, interaction with bacteria and viruses, skin developmental processes, susceptibility to autoimmune diseases, and susceptibility to skin cancer. Genes belonging to the latter two groups are the most frequent. Regarding skin cancer, we find genes involved in squamous cell carcinoma (SCC), melanoma, actinic keratosis, skin hyperpigmentation, and epithelial dysplasia. For autoimmune diseases, we report genes mainly associated with psoriasis, inflammatory arthritis, acute allergic reaction, and ichthyosis.

The significance of the biological functions listed above is also supported by pathway and gene ontology enrichment analyses, which in addition reveal further interesting functions (Additional files 13 and 14). Among the enriched pathways are several involved in apoptosis and tissue homeostasis including apoptotic DNA fragmentation and tissue homeostasis, granzyme Amediated apoptosis, caspase cascade in apoptosis, and the effects of calcineurin in keratinocyte differentiation. Additional significantly enriched pathways include glutamate metabolism activities, which are also revealed by the biological process analysis. Interestingly, glutamate is a key neurotransmitter of the central nervous system, but recent studies show that glutamate receptors are expressed in non-neuronal tissues such as the skin and that glutamate signaling is dysregulated in numerous cancer forms including melanoma [29, 30]. Further pathways include immune-related functions (e.g., B cell receptor signaling pathway, fMLP-induced chemokine gene expression in HMC-1 cells, and MEF2D in T cell apoptosis) and, interestingly, the nitric oxide signaling pathway. Of note, nitric oxide plays diverse biological functions, and in the skin, it is involved in the maintenance of barrier function, melanogenesis, erythema, immunosuppression, and the protection of keratinocytes against UV-induced apoptosis [31, 32]. On the other hand, the biological process analysis reveals phosphate ion metabolism as the most enriched term. Previous studies show that phosphate, a critical element for dividing cells, likely modulates the activity of cancer cells [33], and elevated levels of serum phosphate have been related to lung and skin carcinogeneses in mouse models [34]. Additional enriched terms include regulation of cell polarity and several transport functions (e.g., anion, cation, sodium, and acidic amino transport).

Two exceptional candidate regions are those associated with Deltaproteobacteria (standing communities) and unclassified Betaproteobacteria (active communities), which each contain only a single gene: cadherin 13 (Cdh13) and neural epidermal growth factor-like 2 (Nell2), respectively (Fig. 5). Cdh13 codes for a cell adhesion molecule that is specifically expressed in the basal keratinocytes of the human and mouse epidermis [35]. Cdh13 expression is also observed to be significantly reduced in both invasive cutaneous SCC and psoriasis vulgaris lesions and is thus considered to be an endogenous negative regulator of keratinocyte proliferation and also a crucial preserver of healthy skin architecture [36-38]. Nell2, on the other hand, is reported to be specifically a

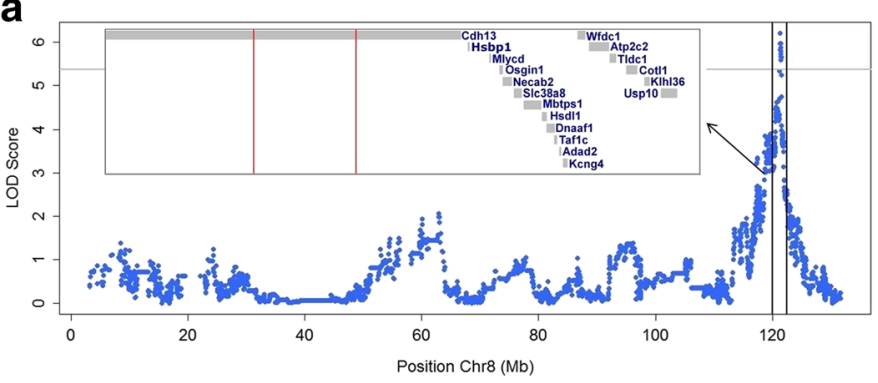

C

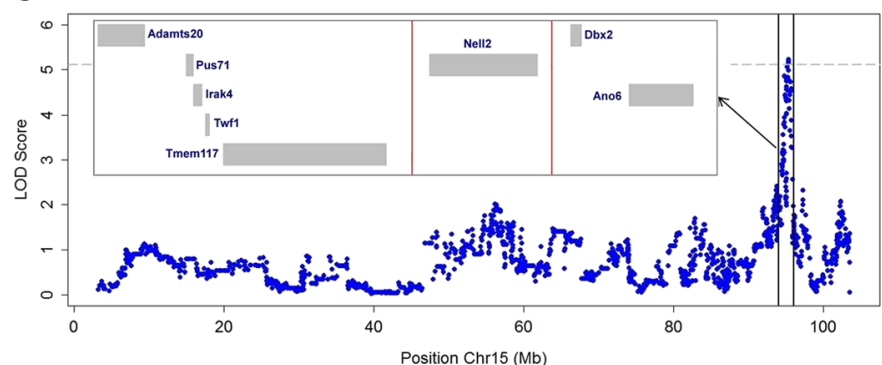

b

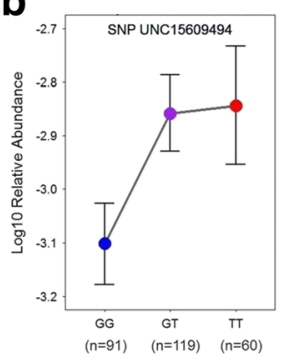

d

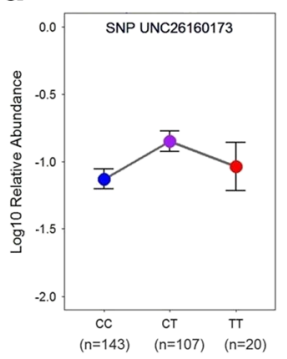

Fig. 5 Candidate regions for Deltaproteobacteria and unclassified Betaproteobacteria traits. a, c Manhattan plots and confidence intervals (red bars) for Deltaproteobacteria and unclassified Betaproteobacteria QTL mapping, respectively. b, d Peak-SNP effect and frequency in QTLs for Deltaproteobacteria and unclassified Betaproteobacteria, respectively. Bars represent SE of the mean. Un unclassified 
expressed in the epidermis (keratinocytes) of patients suffering from atopic dermatitis [39]. Several other noteworthy candidates are described in the "Discussion."

\section{Discussion}

In this study, we performed the first high-resolution genetic mapping of skin microbial traits in the mouse genome. While the overall degree of replication between the $G_{4}$ and $G_{15}$ is low (possible reasons are discussed below), up to five genomic regions display some evidence of overlap between the two cohorts, and the greatly improved results of the $G_{15}$ analysis provide several points of novel insight into the nature of hostmicrobe interactions in the skin. This is on the one hand made possible by the highly advanced nature of the mapping population (i.e., the 15 th generation of an advanced intercross) and high marker density $(>50,000$ informative SNPs). On the other hand, we also introduced a novel means of microbial "phenotyping" in a QTL setting by performing $16 \mathrm{~S}$ rRNA profiling on the transcript level, which proved to be more effective in detecting significant associations. One of the most surprising and intriguing aspects of our findings is the preponderance of identified candidate genes involved in cancer-related processes, which is also supported by aspects of the microbial traits themselves as discussed below.

\section{Comparison between the $\mathrm{G}_{4}$ and $\mathrm{G}_{15}$ populations}

Many potential factors could contribute to the overall lack of replication we observe between the $G_{4}$ and $G_{15}$ study. From the genetic perspective, Greene et al. [40], for example, addressed the question of failing to replicate genetic associations between distinct datasets and concluded (using simulations) that in part, changes in allele frequency can lead to opposite allelic effects on the phenotype. Further, a recent QTL study of the gut microbiota performed on two distinct generations of the same advanced intercross line (generations 4 and 10) similarly replicated and refined only four genomic regions in the more advanced generation, whereby three of the QTLs concerned phylogenetically related traits between cohorts. The authors explained that this poor replication could be due to false-positive QTLs and/or a disparate microbiome composition between the generations as a result of phenotypic and/or genotypic drift [41]. Indeed, in our study, we note significant changes in community composition that occurred between the $G_{4}$ and $G_{15}$, which is not surprising given the movement between two different animal facilities and the multitude of factors concerned with animal husbandry known to influence the microbiome [42].

Moreover, we note that an additional aim of the $G_{4}$ study was to simultaneously evaluate the role of host genetics for skin microbiota composition and susceptibility to autoimmune skin blistering, for which we induced an immunization-based disease model in a subset of the $\mathrm{G}_{4}$ mice [23]. This could in part explain, e.g., the significantly higher proportion of Firmicutes in the $\mathrm{G}_{4}$ compared to the $\mathrm{G}_{15}$ (ANOVA, $p=2.2 \times 10^{-16}$ ), as this phylum is known to dominate the skin microbiota in the context of inflammatory disorders such as psoriasis and atopic dermatitis [43, 44]. However, we note that this difference can not be solely due to disease in the $G_{4}$, as a subset of these animals was not immunized and Firmicutes are uniformly distributed across individuals (Fig. 3b).

Finally, although our mapping approach treats each microbial taxon as an independent trait, microbial abundances may also change in an interrelated manner due to complex community interactions. To determine whether interdependencies between taxa may have changed in the context of the community-level differences we observe between the $G_{4}$ and $G_{15}$, we inspected the interactions between the relative abundances of CMM phyla within each population and indeed observe crucial changes in community interactions. In the $G_{4}$ population, every phylum is strongly negatively correlated with Firmicutes, with Proteobacteria showing the strongest negative association (Fig. $6 \mathrm{a}$ ). In the $\mathrm{G}_{15}$ population, we observe the opposite pattern; every phylum is negatively correlated with Proteobacteria, with Bacteroidetes exhibiting the strongest negative relationship (Fig. 6b). Thus, a change in the overall structure of community interactions between the two cohorts may also alter the nature of host genetic influence on the skin community, i.e., our observations may in part represent gene $\mathrm{x}$ environment interactions.

\section{$16 \mathrm{~S}$ rRNA profiling at the DNA versus RNA level}

Several possible explanations can be provided for the increased success in mapping $16 \mathrm{~S}$ rRNA transcript-level traits. First, in comparison to the bacterial communities inhabiting the lower gastrointestinal tract, the skin harbors a lower biomass and is in constant contact with the environment. Thus, environmental noise from nonresident microbes, which are less likely to display active growth in the skin, is more likely to obscure the signal of resident microbes when 16S rRNA gene profiling is performed at the DNA level. As an example, we more closely examined the QTL analyses between DNA- and RNA-based abundances for unclassified Betaproteobacteria, a taxon for which the two relative abundance estimates are strongly and positively correlated (Spearman's correlation: $\left.r=0.62, p<2.2 \times 10^{-16}\right)$. Additional file 15 shows the Manhattan plot for QTL mapping of unclassified Betaproteobacteria based on DNA and RNA. This reveals a strong overlap between the LOD scores generated for DNA- and RNA-based measurements, but the 

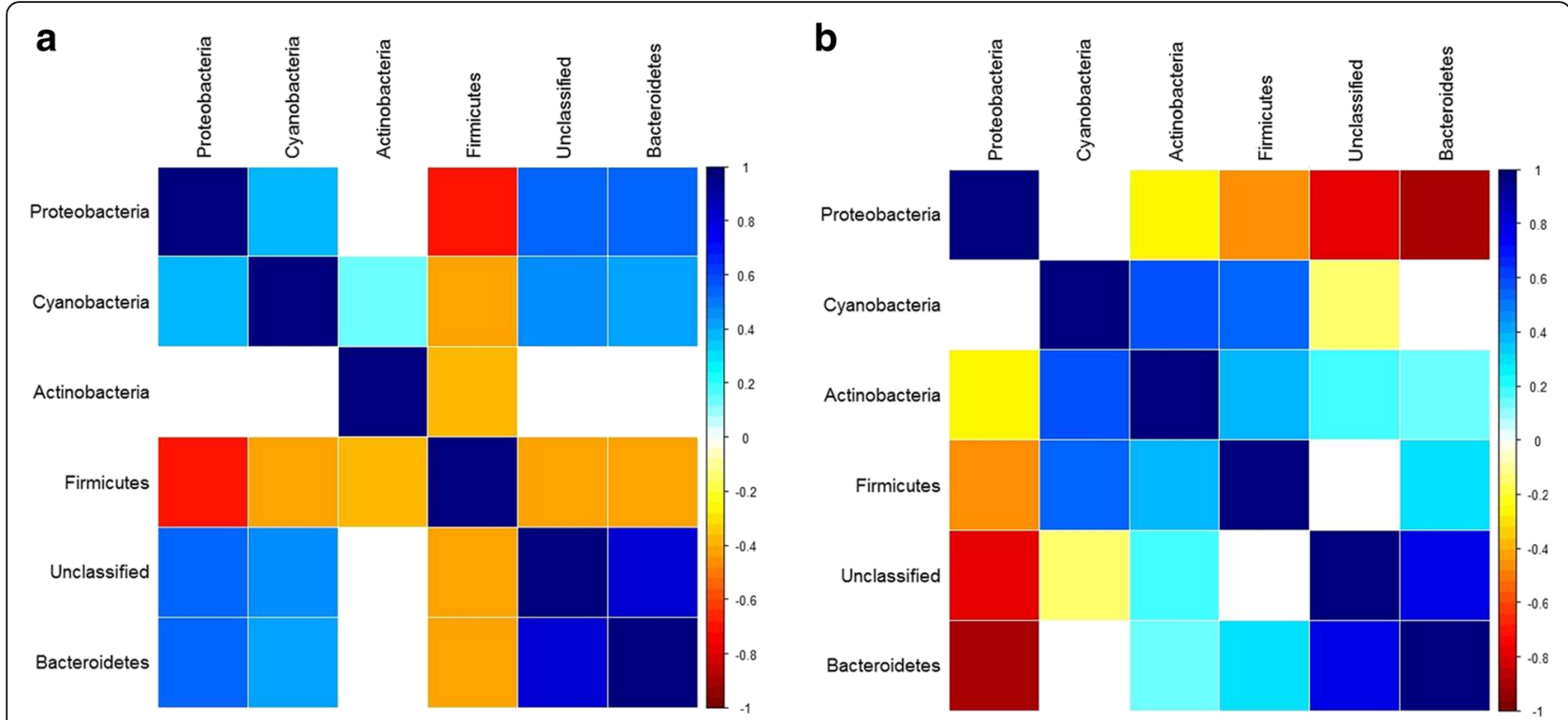

Fig. 6 Correlations among CMM phyla in the standing communities of populations $\mathrm{G}_{4}$ and $\mathrm{G}_{15}$. a $\mathrm{G}_{4}$ population. b $\mathrm{G}_{15}$ population. Nonsignificant correlations ( $p>0.05)$ after multiple testing correction are left blank

peak that defines a significant QTL on the RNA level does not reach the genome-wide significance threshold for DNA.

Second, in contrast to the example of the unclassified Betaproteobacteria QTL described above, we observe an overall poor correlation between the taxon abundances at the DNA versus RNA level, which in some cases is characterized by taxa with high activity but low abundance (see, e.g., unclassified Lachnospiraceae in Fig. 2). Thus, it is likely that many taxa observed at the RNA level are below the limits of reliable measurement at the DNA level. Further, observations at the bacterial transcript level may be more likely to be representative of interaction with the host. This hypothesis is consistent with previous observations of DNA- versus RNA-level bacterial community profiling in a dynamic aquatic habitat, where bacterial activity, but not presence alone, varied along with fluctuations in environmental parameters [45].

\section{Candidate genes and bacterial traits}

In addition to the genomic intervals for which only single genes are present (Cdh13 and Nell2, above), several other regions contain highly interesting candidate genes, whose potential functional role in host-microbe interactions is in some cases further supported by the bacterial traits with which they putatively interact. The QTL for Acinetobacter_OTU51 (RNA level) on chromosome 1 contains a potential immune-related interaction, as the Cops 5 gene (synonyms CSN5, Jab1) found in this interval was shown to influence $\mathrm{T}$ cell development [46], whereas Acinetobacter itself was demonstrated to protect against allergic sensitization and inflammation in the skin by influencing the balance between TH1, TH2, and anti-inflammatory responses [47]. However, Cops5 may alternatively or in addition represent another potential cancer-related interaction, as it is also known to play a critical role in cell proliferation, apoptosis, and regulation of genomic stability and DNA repair [48]. Abnormal expression of Cops5 was demonstrated to impact carcinogenesis in several cancer types including breast cancer, laryngeal cancer, and oral squamous cell carcinoma (SCC) [49-51]. Further, Ivan et al. [52] assessed Cops5 in various melanocytic lesions and found higher expression levels of Cops5 in metastatic melanomas, suggesting that Cops5 may influence the survival and growth of melanoma cells.

As mentioned above, the QTL for Deltaproteobacteria (DNA level) on chromosome 8 contains Cdh13 (Fig. 5), which is expressed in keratinocytes and involved in susceptibility to SCC and malignant melanoma. Interestingly, the Deltaproteobacteria class includes sulfatereducing bacteria that generate hydrogen sulfide $\left(\mathrm{H}_{2} \mathrm{~S}\right)$, which can have genotoxic properties [53] and is implicated in the pathogenesis of ulcerative colitis [54-56], a disease associated with increased colon cancer risk. On the other hand, $\mathrm{H}_{2} \mathrm{~S}$ is also recognized as an endogenous gasotransmitter and was demonstrated to play a functional role in human cutaneous microvasculature [57] and a protective role in systemic sclerosis-associated skin fibrosis [58]. Thus, further functional characterization of potential $\mathrm{H}_{2} \mathrm{~S}$-producing bacteria in the skin and in the context of $C d h 13$ as a regulator of keratinocyte proliferation and skin architecture may be warranted. 
A final highly notable example is the QTL for Halomonas (RNA level) on chromosome 13, which contains the Sox4 gene belonging to the SoxC class of transcription factors. Sox 4 is known to inhibit apoptosis and increase proliferation and is thus highly linked to carcinogenesis [59]. Foronda et al. [60] further addressed the role of Sox4 (which is the only member of the SoxC class that is expressed in the skin) in skin homeostasis and cancer by making a skin-specific deletion of Sox4 in combination with a chemically induced carcinogenesis model. The authors report reduced tumor progression and number in Sox4-deficient mice compared to wild type, indicating an oncogenic activity of Sox 4 in the skin. Interestingly, extracts from Halomonas meridiana bacteria isolated from brine pools of the Red Sea were demonstrated to have significant anticancer activity (apoptosis) in human cancer cell lines [61], raising the intriguing possibility that resident skin microbes play a role in endogenous anticancer activity from a hologenomic perspective.

\section{Conclusions}

The path from QTL mapping to gene/mutation identification and functional characterization is complex and challenging. Through the use of high-resolution mapping and the introduction of phenotyping based on microbial activity, our study makes a substantial step towards understanding the host genetic component to interindividual variability in the skin microbiota and its potentially important fitness consequences. In particular, the preponderance of cancer-related candidate genes identified should motivate greater attention to the role of host-microbe interactions in cancer susceptibility and their potential as preventative and/or therapeutic targets. Finally, we suggest that adding activity-based community profiling may greatly enhance the capability to detect biologically meaningful host-microbe interactions in a wide variety of microbiome study settings.

\section{Methods}

Animals and skin sample collection

MRL/MpJ, NZM2410/J, BXD2/TyJ, and CAST/EiJ mice were purchased from the Jackson Laboratory (Maine, USA) and kept under conventional conditions. To generate a heterogeneous intercross line, these individuals were intercrossed at an equal strain and sex distribution as described previously [23]. Male and female offspring used in the study were transferred to separate cages according to family. Animals were held under specific pathogen-free conditions at a 12-h light/dark cycle with food and water ad libitum. All 270 animals (98 males and 172 females) were housed in the University of Lübeck, Germany, and sampled from the 15th generation of this advanced intercross line at a mean age of 5.9 months. All animal experiments were approved by the "Ministerium für Energiewende, Landwirtschaft, Umwelt und ländliche Räume des Landes SchleswigHolstein" in Kiel, Germany (reference number: V 31272241. 122-5 (12-2/09)).

An identical region from the left ear of each mouse was sampled, snap frozen, and stored at $-80{ }^{\circ} \mathrm{C}$ until processing. During the dissection process, tools were carefully sterilized by flaming $70 \%$ ethanol. Total DNA and RNA were extracted simultaneously using the AllPrep DNA/RNA Qiagen kit. The working surface and pipettes were decontaminated with RNase AWAY ${ }^{\circ}$ (Thermo Fisher Scientific). An additional 2-h room temperature incubation step was included after homogenization in order to increase the nucleic acids' dissolution in the RLT buffer. RNA was treated with DNase (RNase-Free DNase Qiagen, stock solution concentration) for $15 \mathrm{~min}$, twice. cDNA synthesis was performed using High-Capacity cDNA Reverse Transcription Kits (Applied Biosystems). In addition, RNA purity was checked by a negative reverse transcriptase (without transcriptase) PCR and agarose gel electrophoresis.

\section{S rRNA gene sequencing and processing}

We amplified the V1-V2 regions of the bacterial $16 \mathrm{~S}$ rRNA gene following a dual indexing approach for each sample. The primer pair (5'-AATGATACGGCGACCACCGAGATCTACACXXXXXXXXTATGGTAATTGT AGAGTTTGATCCTGGCTCAG-3') and (5'CAAGCAGAAGACGGCATACGAGATXXXXXXXXAGTCAGTCAGCC TGCTGCCTCCCGTAGGAGT-3') contains the Illumina P5 (forward) and P7 (reverse), denoted by italics, whereas the underlined italic sequences represent the broadly conserved bacterial primers $27 \mathrm{~F}$ and 338R. A 12-base linker sequence (underlined only) was added to the bacterial primer in order to increase the annealing temperature of the sequencing primer, as recommended by Illumina. Both primers contained a unique eight-base multiplex identifier (Index; designated as XXXXXXXX) in order to tag each PCR product. PCR amplifications were conducted in a $12.5-\mu \mathrm{L}$ volume containing $100 \mathrm{ng}$ of either DNA or cDNA template using the Phusion ${ }^{\circ}$ Hot Start II DNA High-Fidelity DNA Polymerase (Finnzymes, Espoo, Finland). Cycling conditions were as follows: initial denaturation for $30 \mathrm{~s}$ at $98{ }^{\circ} \mathrm{C}$; 35 cycles of $9 \mathrm{~s}$ at $98{ }^{\circ} \mathrm{C}, 30 \mathrm{~s}$ at $55{ }^{\circ} \mathrm{C}$, and $30 \mathrm{~s}$ at $72{ }^{\circ} \mathrm{C}$ for DNA, 30 cycles of $9 \mathrm{~s}$ at $98{ }^{\circ} \mathrm{C}, 30 \mathrm{~s}$ at $55^{\circ} \mathrm{C}$, and $30 \mathrm{~s}$ at $72{ }^{\circ} \mathrm{C}$ for cDNA; final extension for $10 \mathrm{~min}$ at $72{ }^{\circ} \mathrm{C}$. Reactions were duplicated and products were merged in order to obtain a final volume of $25-\mu \mathrm{L}$ PCR for each sample. Negative controls were performed using blank (template-free) reactions with different combinations of forward and reverse primers such that all primers were checked for contamination, which were required to be 
negative as inclusion criteria. Further, negative extraction controls for each round of DNA/RNA extraction $(n=14$, i.e., in total, 28 negative extraction controls, as DNA and RNA are split during the procedure) were included. For all samples, PCR product concentrations were first quantified on an agarose gel using image analysis software (Bio-Rad). After quantification, products were mixed together to make equimolar subpools. Subpools were then extracted from agarose gel with the Qiagen MinElute Gel Extraction Kit and quantified with the Quant-iT $^{\mathrm{TM}}$ dsDNA BR Assay Kit on a Qubit fluorometer (Invitrogen). Finally, subpools were combined in one equimolar pool for each library. Pools were further purified using AMPure ${ }^{\circledR}$ Beads (Agencourt), and complete libraries were run on an Agilent Bioanalyzer prior to sequencing, as recommended by Illumina. The Amplicon libraries were sequenced on a MiSeq using the MiSeq Reagent Kit v3 600 cycles sequencing chemistry.

No mismatch to the barcode was allowed while demultiplexing (CASAVA, Illumina). Raw forward and reverse reads were merged in USEARCH (v.7) [62] as follows: forward and reverse reads were truncated before alignment at the first base where the quality score dropped below $Q=2$; the maximum number of mismatches allowed in the overlap region was 2 ; the minimum length of the forward and reverse reads after truncating was $200 \mathrm{bp}$; the minimum length of the overlap region was $150 \mathrm{bp}$; the minimum length of the merged read was $270 \mathrm{bp}$; the maximum length of the merged read was $330 \mathrm{bp}$. Merged reads were filtered by the parameter of expected error $(E=0.5)$, as recommended [63]. Finally, chimeric sequences were removed in UCHIME [64] using the SILVA Gold reference database [65].

\section{Taxonomic classification and OTU binning}

RDP Multi-Classifier (v.9.0) [66] implemented in Mothur (v.31) [67] was applied to assign taxonomy from the phylum to the genus level using a 0.80 confidence threshold and 1000 iterations. Sequences classified as Archaea, unknown, or Mitochondria were removed. Afterwards, sequences were aligned to the SILVA reference database. Sequences that failed to align were excluded. To avoid spurious OTUs, aligned sequences were further de-noised using the pre-cluster algorithm executed in Mothur, as recommended by Schloss et al. [68]. Prior to OTU binning, samples were rarefied to an even sequence depth of 3500, except for one sample that had 3134 reads, in order to control for varied sequencing depth and biases in ecological community analysis. Operational taxonomic units were binned at a 97\% similarity threshold using the Mothur average clustering algorithm.

\section{SNP genotyping and founder haplotype reconstruction} Genomic DNA was isolated from liver tissue and incubated in $500 \mu \mathrm{L}$ of $50 \mathrm{mM} \mathrm{NaOH}$ at $95{ }^{\circ} \mathrm{C}$ for $2 \mathrm{~h}$. The reaction was neutralized by the posterior addition of $50 \mu \mathrm{L}$ of $1 \mathrm{M}$ Tris- $\mathrm{HCl}$ ( $\mathrm{pH} 8.0$ ). DNA was further processed with DNeasy Blood \& Tissue Kit (Qiagen) according to the manufacturer's instructions. The extracted DNA was quantified using NanoDrop and normalized to $50 \mathrm{ng} / \mu \mathrm{L}$ in TE buffer $(10 \mathrm{mM}$ Tris, $1 \mathrm{mM}$ EDTA; $\mathrm{pH}=$ $8)$. We used the high-density mouse universal genotyping array, MegaMuga (Illumina), which can hybridize up to 77,800 SNPs, to genotype the mice as well as the four founder individuals. Raw genotyping data were first analyzed using GenomeStudio Data Analysis Software (Illumina). Then, using PLINK (v.1.07) [69], SNPs missing in the founder individuals and SNPs with a minor allele frequency of $10 \%$ or below were removed. We obtained 53,203 informative SNP markers distributed genomewide, with an average spacing of $0.04 \mathrm{Mb}$ and standard deviation of $0.09 \mathrm{Mb}$. The four founder haplotype probabilities were calculated at each SNP marker for every sample by splitting the chromosomes using the "hdesign" function from the "HAPPY" (v.2.4) R package [70].

\section{Core Measurable Microbiota}

To determine the set of microbial traits to be included in the QTL mapping, we defined a Core Measurable Microbiota (CMM) to include only bacterial taxa (genus to phylum level) with at least five reads in at least half of the samples, and species-level OTUs with at least five reads in at least one third of the samples. These thresholds were applied to the DNA- and RNA-based datasets separately, whereby in total 92 taxa (genus to phylum level) and 44 OTUs were included. We added a value of 0.5 to the absolute abundances of all CMMs, and then converted the absolute abundances into relative abundances. In order to reduce skewness, relative abundances were $\log _{10}$-transformed.

\section{SourceTracker analysis}

SourceTracker [26] analysis was performed on the level of mapped genera and species-level OTUs (97\% similarity threshold) under default parameters. The training set included the negative extraction controls for which a weak PCR product was detectable and sufficient post quality filtering read number was achieved (16 out of 28 with $>1000$ reads, remaining samples containing 1 to 797 (mean 99) reads or no PCR product).

\section{Summary statistics of the CMMs and partitioning of variance}

All statistical analyses were performed in R (v.3.2.2) [71]. In order to assess the magnitude of variability of the CMMs, summary statistics were calculated on each 
CMM (taxa and OTUs). Multivariate analysis of variance was applied on the CMMs $\log _{10}$-transformed relative abundances. We tested the effects of weight, gender, age, and cage environment on the variation in the CMM relative abundances in DNA- and RNA-based datasets; the three latter factors showed a significant overall effect $(p \leq 0.05)$ and were thus included in the QTL mapping model. To measure the effects of these factors on variation in CMM trait abundances across samples, we built a mixed effects model in the "lme4" (v.1.1-10) R package [72] for each CMM trait (taxa and OTUs) in the DNAand RNA-based datasets, which included gender and age as fixed factors and cage as a random term. The variance components were measured using the "VarCorr" function. Marginal $R^{2}$, which represents the proportion of variance explained by fixed factors [73], was calculated using the "r.squaredGLMM" function in the "MuMIn" (v.1.15.1) R package [74].

\section{QTL mapping}

Linkage mapping was performed with a mixed model approach using the "QTLRel" (v. 0.2-14) R package [75] in DOQTL (v. 1.2.0) [76]. We fit an additive model that regresses the $\log _{10}$-transformed relative abundances of each CMM trait (taxa and OTUs) on the four founder haplotype contributions. To adjust for different degrees of mice relatedness, a kinship matrix was defined by calculating correlation coefficients between samples using the "kinship.probs" function from the DOQTL package. The kinship matrix was incorporated into the model instead of pedigree records, as recommended by Svenson et al. [77] and Gatti et al. [76]. Gender and age (expressed in days) were incorporated as fixed covariates and cage as a random term in the mapping model. To determine significance thresholds for the LOD scores of each marker/trait, we applied a permutation procedure described by Churchill and Doerge [78]. This procedure consists of shuffling the phenotypes (i.e., the $\log _{10}$ relative abundances) across the genotypes and re-runs the QTL model to generate new LOD scores. We repeated this process 5000 times for each marker/trait. Afterwards, using the newly generated distribution of LOD scores, we determined the 90th and 95th percentiles and used them to define the suggestive $(0.1)$ and significant thresholds, respectively. Finally, we compared the LOD scores generated in the original QTL scan to the defined significance thresholds: suggestive (genome-wide alpha $\leq$ 0.1 ) and significant (genome-wide alpha $\leq 0.05$ ). Only the LOD scores that met or exceeded either the suggestive or significant thresholds were considered to indicate the presence of a putative QTL and reported in our results. We set QTL confidence intervals at 1.5 LOD drops on either side of the peak position.

\section{Quantitative and ecological analysis}

Alpha diversity indices (i.e., Shannon entropy and Chao1) were calculated in the "vegan" (v.2.3.0) R package [79] on the entire dataset at both the genus and OTU levels. For each alpha diversity measure, we calculated summary statistics and partitioning of variance and performed QTL mapping only for Chao1, as described above. Comparison of mean relative abundances of major phyla and genera between the standing and active communities was performed using a paired Wilcoxon test. The correlation of relative abundances between the standing and active dataset was performed using Spearman's correlation. Correlations between the abundances of major phyla in the standing communities of generations 4 and 15 were calculated using Spearman's correlation in the "Hmisc" (v.3.17-0) R package [80]. $p$ values were adjusted using the Benjamini and Hochberg method [27], and correlation coefficients were visualized using the "corrplot" (v.0.73) R package [81].

\section{Real-time quantification of bacterial traits}

$16 \mathrm{~S}$ rRNA gene primers targeting Betaproteobacteria, Epsilonproteobacteria, Streptococcus, and total bacteria were used to perform real-time quantification on a random subset of 80 out of the 270 mice. The taxonspecific primers include F_AACGCGAAAAACCTTACCTACC and R_TGCCCTTTCGTAGCAACTAGTG for Betaproteobacteria, F_TAGGCTTGACATTGATAGAATC and R_CTTACGAAGGCAGTCTCCTTA for Epsilonproteobaceria [82], F_CTWACCAGAAAGGGACGGCT and R_AAGGRYCYAACACCTAGC for Streptococcus [83], and F_ACTCCTACGGGAGGCAGCAG and R_ATTACCGCGGCTGCTGG for total bacteria [84]. Real-time quantitative PCR was carried out in a volume of $10 \mu \mathrm{L}$ on a PikoReal Real-Time PCR System using 96-well plates and three technical replicates for each sample. Each PCR mixture consisted of $5 \mu \mathrm{L}$ of PowerUp SYBR PCR Master Mix (Applied Biosystems), $0.5 \mu \mathrm{L}$ of each primer $(10 \mu \mathrm{M}), 2.5 \mu \mathrm{L}$ of water, and $2 \mu \mathrm{L}$ of the original cDNA template used for $16 \mathrm{~S}$ rRNA gene sequencing (1:20 dilution). The amplification program consisted of (i) initial step at $95^{\circ} \mathrm{C}$ for $10 \mathrm{~min}$, (ii) $45 \mathrm{cy}$ cles of denaturation at $95{ }^{\circ} \mathrm{C}$ for $15 \mathrm{~s}$ and annealing/extension at $60{ }^{\circ} \mathrm{C}$ for $1 \mathrm{~min}$, and (iii) 1 cycle at $60{ }^{\circ} \mathrm{C}$ for $30 \mathrm{~s}$ and a melt ramp from 60 to $95{ }^{\circ} \mathrm{C}$. The relative quantification of a given bacterial trait was determined by comparing taxon-specific and total bacteria $C_{\mathrm{T}}$ values as expressed $2^{- \text {(delta-delta } C_{\mathrm{T}} \text { values) }}$.

\section{Pathway and gene ontology enrichment analysis}

For the enrichment analysis, we selected a list of genes that includes the two nearest genes to the peak SNP on either side of the chromosome (maximum four genes 
per interval) and performed the analyses based on two categories including pathways (Biocarta) and ontologies (Biological Processes). We used the tool Enrichr [85] and sorted the results based on the combined score from the enrichment analysis.

\section{Additional files}

Additional file 1: Figure S1. Principal coordinate analysis of beta diversity indices of skin microbiota in populations $G_{15}$ and $G_{4}$. (A) BrayCurtis, (B) Jaccard indices. Indices are calculated on genera abundances after normalization of sequencing depth to 2500 reads per sample in both populations $G_{15}$ and $G_{4}$. DNA: standing, $R N A$ : active. Goodness of fit: Bray-Curtis, $r^{2}=0.38, p=1.10^{-5} ;$ Jaccard, $r^{2}=0.47, p=1.10^{-5}$, based on 1000 permutations. SD: standard deviation. (TIF $392 \mathrm{~kb}$ )

Additional file 2: Table S1. Summary statistics of CMM taxa and alpha diversity indices as profiled based on DNA. Means, standard deviations (STD), minimum (Min), maximum (Max), and coefficient of variation (CV) values of relative abundances in population $\mathrm{G}_{15}(n=270)$. When taxa are redundant, only the lowest rank is shown. Un: unclassified. (XLSX $15 \mathrm{~kb}$ )

Additional file 3: Table S2. Summary statistics of CMM taxa and alpha diversity indices as profiled based on RNA. Means, standard deviations (STD), minimum (Min), maximum (Max), and coefficient of variation (CV) values relative abundances in population $\mathrm{G}_{15}(n=270)$. When taxa are redundant, only the lowest rank is shown. Un: unclassified. (XLSX $15 \mathrm{~kb}$ )

Additional file 4: Table S3. Summary statistics of CMM OTUs and alpha diversity indices as profiled based on DNA. Means, standard deviations (STD), minimum (Min), maximum (Max), and coefficient of variation (CV) values of relative abundances in population $G_{15}(n=270)$. Un: unclassified. (XLSX $12 \mathrm{~kb}$ )

Additional file 5: Table S4. Summary statistics of CMM OTUs and alpha diversity indices as profiled based on RNA. Means, standard deviations (STD), minimum (Min), maximum (Max), and coefficient of variation (CV) values of relative abundances in population $G_{15}(n=270)$. Un: unclassified. (XLSX $12 \mathrm{~kb}$ )

Additional file 6: Table S5. Estimates of proportions of explained variance by explanatory variables for genus- to phylum-level taxa (DNA) Estimates for random components (cage and residual) and fixed terms (gender and age) are calculated for each of the CMM taxa $\log _{10}$-relative abundances and alpha diversity indices as profiled based on DNA in population $\mathrm{G}_{15}(n=270)$. When taxa are redundant, only the lowest rank is shown. Un: unclassified. (XLSX $14 \mathrm{~kb}$ )

Additional file 7: Table S6. Estimates of proportions of explained variance by explanatory variables for genus- to phylum-level taxa (RNA). Estimates for random components (cage and residual) and fixed terms (gender and age) are calculated for each of the CMM taxa $\log _{10}$-relative abundances and alpha diversity indices as profiled based on RNA in $G_{15}$ $(n=270)$. When taxa are redundant, only the lowest rank is shown. Un: unclassified. (XLSX $14 \mathrm{~kb}$ )

Additional file 8: Table S7. Estimates of proportions of explained variance by explanatory variables for OTUs (DNA). Estimates for random components (cage and residual) and fixed terms (gender and age) are calculated for each of the CMM OTUs $\log _{10}$-relative abundances and alpha diversity indices as profiled based on DNA in $G_{15}(n=270)$. When taxa are redundant, only the lowest rank is shown. Un: unclassified. (XLSX 13 kb)

Additional file 9: Table S8. Estimates of proportions of explained variance by explanatory variables for OTUs (RNA). Estimates of proportions of explained variance by random components (cage and residual) and fixed terms (gender and age) are calculated for each of the CMM OTUs $\log _{10}$-relative abundances and alpha diversity indices as profiled based on RNA in $G_{15}(n=270)$. When taxa are redundant, only the lowest rank is shown. Un: unclassified. (XLSX 13 kb)

Additional file 10: Table S9. Residuals of the linear mixed models for all mapped taxa and alpha diversity measures. Un: unclassified. (XLSX $1069 \mathrm{~kb})$
Additional file 11: Figure S2. Manhattan plot of Neisseria_OTU1320 QTL mapping. Significant thresholds $(p \leq 0.05)$ are shown in a continuous line; suggestive thresholds $(p \leq 0.10)$ are shown in a discontinuous line. Chr: chromosome. (TIF $219 \mathrm{~kb}$ )

Additional file 12: Table S10. Functions of the potential candidate genes. Un: unclassified. (XLSX $15 \mathrm{~kb}$ )

Additional file 13: Figure S3. Pathway and biological process enrichment analysis of candidate regions. A. Pathways analysis (Biocarta). B. Biological processes. Significant enrichment results after correction for multiple testing $(p \leq 0.1)$ are displayed in color; non-significant enriched terms are colorless. For the biological process analysis, only combined scores higher than 2.5 are reported. (TIF $581 \mathrm{~kb}$ )

Additional file 14: Table S11. Full details of pathway and biological process enrichment analyses for candidate regions. (XLSX $71 \mathrm{~kb}$ )

Additional file 15: Figure S4. Manhattan plot for unclassified Betaproteobacteria QTL. Significant thresholds $(p \leq 0.05)$ are shown in a continuous line; suggestive thresholds $(p \leq 0.1)$ are shown in a discontinuous line. Chr: chromosome, Un: unclassified. (TIF 572 kb)

\section{Abbreviation}

OTU: Operational taxonomic unit

\section{Acknowledgements}

We thank Susen Mueller and Artem Vorobyev for assisting with mouse work; Katja Cloppenborg-Schmidt for excellent technical assistance; Britt Marie Hermes, Jun Wang, Philipp Rausch, and Marie Vallier for helpful discussion; and the International Max Planck Research School (IMPRS) for Evolutionary Biology.

\section{Funding}

This work was supported by the German Science Foundation (DFG) grants RTG 1743 "Genes, Environment and Inflammation," Excellence Cluster 306 "Inflammation at Interfaces," and Clinical Research Unit 303 "Pemphigoid Dieseases - Molecular Pathways and their Therapeutic Potential."

\section{Availability of data and materials}

Bacterial 16S rRNA gene sequences are deposited at the European Nucleotide Archive, PRJEB15403.

\section{Authors' contributions}

SI and JB designed the study, SK performed the Miseq sequencing, YG designed the pipeline for QTL mapping, MB performed the analyses, and MB and JB wrote the manuscript. All authors read and approved the final manuscript.

\section{Competing interests}

The authors declare that they have no competing interests.

\section{Consent for publication}

Not applicable

\section{Ethics approval and consent to participate}

All animal experiments were approved by the "Ministerium für Energiewende, Landwirtschaft, Umwelt und ländliche Räume des Landes Schleswig-Holstein" in Kiel, Germany (reference number: V 312-72241. 122-5 (12-2/09)).

\section{Publisher's Note}

Springer Nature remains neutral with regard to jurisdictional claims in published maps and institutional affiliations.

\section{Author details}

'Max Planck Institute for Evolutionary Biology, August-Thienemann-Str. 2, 24306 Plön, Germany. ${ }^{2}$ Institute for Experimental Medicine,

Christian-Albrechts-University of Kiel, Arnold-Heller-Str. 3, 24105 Kiel, Germany. ${ }^{3}$ Lübeck Institute of Experimental Dermatology, University of Lübeck, Lübeck, Germany. 


\section{Received: 3 October 2016 Accepted: 15 May 2017} Published online: 06 June 2017

\section{References}

1. Human Microbiome Project Consortium. Structure, function and diversity of the healthy human microbiome. Nature. 2012;486(7402):207-14.

2. Ley RE, Turnbaugh PJ, Klein S, Gordon J. Microbial ecology: human gut microbes associated with obesity. Nature. 2006;444(7122):1022-3.

3. McKnite AM, Perez-Munoz ME, Lu L, Williams EG, Brewer S, Andreux PA, Bastiaansen JW, Wang X, Kachman SD, Auwerx J, Williams RW, Benson AK, Peterson DA, Ciobanu DC. Murine gut microbiota is defined by host genetics and modulates variation of metabolic traits. PLoS One. 2012;7(6):e39191.

4. Stappenbeck TS, Hooper LV, Gordon JI. Developmental regulation of intestinal angiogenesis by indigenous microbes via Paneth cells. Proc Natl Acad Sci U S A. 2002:99(24):15451-5.

5. Linnenbrink M, Wang J, Hardouin EA, Künzel S, Metzler D, Baines JF. The role of biogeography in shaping diversity of the intestinal microbiota in house mice. Mol Ecol. 2013;22(7):1904-16.

6. Song SJ, Lauber C, Costello EK, Lozupone CA, Humphrey G, Berg-Lyons D, Caporaso JG, Knights D, Clemente JC, Nakielny S, Gordon Jl, Fierer N, Knight R. Cohabiting family members share microbiota with one another and with their dogs. Elife. 2013;2:e00458.

7. Org E, Parks BW, Joo JW, Emert B, Schwartzman W, Kang EY, Mehrabian M, Pan C, Knight Gunsalus R, Drake TA, Eskin E, Lusis AJ. Genetic and environmental control of host-gut microbiota interactions. Genome Res. 2015:25(10):1558-69.

8. $\quad \mathrm{Xu} Z$, Knight R. Dietary effects on human gut microbiome diversity. Br J Nutr. 2015;113 Suppl 0:S1-5.

9. Goodrich JK, Waters JL, Poole AC, Sutter JL, Koren O, Blekhman R, Beaumont M, Van Treuren W, Knight R, Bell JT, Spector TD, Clark AG, Ley RE. Human genetics shape the gut microbiome. Cell. 2014;159(4):789-99.

10. Goodrich JK, Davenport ER, Beaumont M, Jackson MA, Knight R, Ober C, Spector TD, Bell JT, Clark AG, Ley RE. Genetic determinants of the gut microbiome in UK twins. Cell Host Microbe. 2016;19(5):731-43.

11. Kovacs A, Ben-Jacob N, Tayem H, Halperin E, Iraqi FA, Gophna U. Genotype is a stronger determinant than sex of the mouse gut microbiota. Microb Ecol. 2011:61(2):423-8.

12. Campbell JH, Foster CM, Vishnivetskaya T, Campbell AG, Yang ZK, Wymore A, Palumbo AV, Chesler EJ, Podar M. Host genetic and environmental effects on mouse intestinal microbiota. ISME J. 2012;6(11):2033-44.

13. Benson AK, Kelly SA, Legge R, Ma F, Low SJ, Kim J, Zhang M, Oh PL, Nehrenberg D, Hua K, Kachman SD, Moriyama EN, Walter J, Peterson DA, Pomp D. Individuality in gut microbiota composition is a complex polygenic trait shaped by multiple environmental and host genetic factors. Proc Natl Acad Sci U S A. 2010;107(44):18933-8.

14. Wang J, Kalyan S, Steck N, Turner LM, Harr B, Künzel S, Vallier M, Häsler R, Franke A, Oberg HH, Ibrahim SM, Grassl GA, Kabelitz D, Baines JF. Analysis of intestinal microbiota in hybrid house mice reveals evolutionary divergence in a vertebrate hologenome. Nat Commun. 2015;6:6440.

15. Davenport ER, Cusanovich DA, Michelini K, Barreiro LB, Ober C, Gilad Y. Genome-wide association studies of the human gut microbiota. PLoS One. 2015;10(11):e0140301.

16. Blekhman R, Goodrich JK, Huang K, Sun Q, Bukowski R, Bell JT, Spector TD, Keinan A, Ley RE, Gevers D, Clark AG. Host genetic variation impacts microbiome composition across human body sites. Genome Biol. 2015;16:191.

17. Bonder MJ, Kurilshikov A, Tigchelaar E, Mujagic Z, Imhann F, Vila AV, Deelen P, Vatanen T, Schirmer M, Smeekens SP, Zhernakova DV, Jankipersadsing SA, Jaeger M, Oosting M, Cenit MC, Masclee AA, Swertz MA, Li Y, Kumar V, Joosten L, Harmsen H, Weersma RK, Franke L, Hofker MH, Xavier RJ, Jonkers D, Netea MG, Wijmenga C, Fu J, Zhernakova A. The effect of host genetics on the gut microbiome. Nat Genet. 2016:48(11):1407-12.

18. Turpin W, Espin-Garcia O, Xu W, Silverberg MS, Kevans D, Smith MI, Guttman DS, Griffiths A, Panaccione R, Otley A, Xu L, Shestopaloff K, Moreno-Hagelsieb G, GEM Project Research Consortium, Paterson AD, Croitoru K. Association of host genome with intestinal microbial composition in a large healthy cohort. Nat Genet. 2016;48(11):1413-7.

19. Wang J, Thingholm LB, Skiecevičienè J, Rausch P, Kummen M, Hov JR, Degenhardt F, Heinsen FA, Rühlemann MC, Szymczak S, Holm K, Esko T, Sun J, Pricop-Jeckstadt M, Al-Dury S, Bohov P, Bethune J, Sommer F, Ellinghaus D, Berge RK, Hübenthal M, Koch M, Schwarz K, Rimbach G, Hübbe P, Pan WH, Sheibani-Tezerji R, Häsler R, Rosenstiel P, D'Amato M, Cloppenborg-
Schmidt K, Künzel S, Laudes M, Marschall HU, Lieb W, Nöthlings U, Karlsen $\mathrm{TH}$, Baines JF, Franke A. Genome-wide association analysis identifies variation in vitamin $\mathrm{D}$ receptor and other host factors influencing the gut microbiota. Nat Genet. 2016:48(11):1396-406.

20. Grice EA, Kong HH, Renaud G, Young AC, NISC Comparative Sequencing Program, Bouffard GG, Blakesley RW, Wolfsberg TG, Turner ML, Segre JA. A diversity profile of the human skin microbiota. Genome Res. 2008;18(7): 1043-50.

21. Grice EA, Kong HH, Conlan S, Deming CB, Davis J, Young AC, NISC Comparative Sequencing Program, Bouffard GG, Blakesley RW, Murray PR, Green ED, Turner ML, Segre JA. Topographical and temporal diversity of the human skin microbiome. Science. 2009;324(5931):1190-2.

22. Costello EK, Lauber CL, Hamady M, Fierer N, Gordon Jl, Knight R. Bacterial community variation in human body habitats across space and time. Science. 2009:326(5960):1694-7.

23. Srinivas G, Möller S, Wang J, Künzel S, Zillikens D, Baines JF, Ibrahim SM. Genome-wide mapping of gene-microbiota interactions in susceptibility to autoimmune skin blistering. Nat Commun. 2013;4:2462.

24. Kong HH, Andersson B, Clavel T, Common JE, Jackson SA, Olson ND, Segre JA, Traidl-Hoffmann C. Performing skin microbiome research: a method to the madness. J Invest Dermatol. 2017;137:561-8.

25. Salter SJ, Cox MJ, Turek EM, Calus ST, Cookson WO, Moffatt MF, Turner P, Parkhill J, Loman NJ, Walker AW. Reagent and laboratory contamination can critically impact sequence-based microbiome analyses. BMC Biol. 2014;12:87.

26. Knights D, Kuczynski J, Charlson ES, Zaneveld J, Mozer MC, Collman RG, Bushman FD, Knight R, Kelley ST. Bayesian community-wide cultureindependent microbial source tracking. Nat Methods. 2011;8(9):761-3.

27. Benjamini $Y$, Hochberg $Y$. Controlling the false discovery rate: a practical and powerful approach to multiple testing. J R Stat Soc B Methodol. 1995;57:289-300.

28. Si J, Lee S, Park JM, Sung J, Ko G. Genetic associations and shared environmental effects on the skin microbiome of Korean twins. BMC Genomics. 2015;16:992.

29. Fuziwara S, Inoue K, Denda M. NMDA-type glutamate receptor is associated with cutaneous barrier homeostasis. J Invest Dermatol. 2003;120(6):1023-9.

30. Hoogduijn MJ, Hitchcock IS, Smit NP, Gillbro JM, Schallreuter KU, Genever PG. Glutamate receptors on human melanocytes regulate the expression of MiTF. Pigment Cell Res. 2006;19:58-67.

31. Cals-Grierson MM, Ormerod AD. Nitric oxide function in the skin. Nitric Oxide. 2004;10(4):179-93.

32. Chang HR, Tsao DA, Wang SR, Yu HS. Expression of nitric oxide synthases in keratinocytes after UVB irradiation. Arch Dermatol Res. 2003;295(7):293-6.

33. Ramirez CP, Fiedler D. Investigating the role of inorganic phosphate in tumor metabolism and metastasis. Cancer Metab. 2014;2 Suppl 1:55.

34. Camalier CE, Young MR, Bobe G, Perella CM, Colburn NH, Beck Jr GR. Elevated phosphate activates $\mathrm{N}$-ras and promotes cell transformation and skin tumorigenesis. Cancer Prev Res (Phila). 2010;3(3):359-70.

35. Zhou S, Matsuyoshi N, Liang SB, Takeuchi T, Ohtsuki Y, Miyachi Y. Expression of T-cadherin in basal keratinocytes of skin. J Invest Dermatol. 2002;118(6):1080-4.

36. Mukoyama $Y$, Zhou S, Miyachi $Y$, Matsuyoshi N. T-cadherin negatively regulates the proliferation of cutaneous squamous carcinoma cells. J Invest Dermatol. 2005;124(4):833-8.

37. Kuphal S, Martyn AC, Pedley J, Crowther LM, Bonazzi VF, Parsons PG, Bosserhoff AK, Hayward NK, Boyle GM. H-cadherin expression reduces invasion of malignant melanoma. Pigment Cell Melanoma Res. 2009;22(3):296-306.

38. Li L, Jiang M, Feng Q, Kiviat NB, Stern JE, Hawes S, Cherne S, Lu H. Aberrant methylation changes detected in cutaneous squamous cell carcinoma of immunocompetent individuals. Cell Biochem Biophys. 2015;72(2):599-604.

39. Kamsteeg M, Bergers M, de Boer R, Zeeuwen PL, Hato SV, Schalkwijk J, Tjabringa GS. Type 2 helper T-cell cytokines induce morphologic and molecular characteristics of atopic dermatitis in human skin equivalent. Am J Pathol. 2011;178(5):2091-9.

40. Greene CS, Penrod NM, Williams SM, Moore JH. Failure to replicate a genetic association may provide important clues about genetic architecture PLoS One. 2009:4(6):e5639.

41. Leamy LJ, Kelly SA, Nietfeldt J, Legge RM, Ma F, Hua K, Sinha R, Peterson DA, Walter J, Benson AK, Pomp D. Host genetics and diet, but not immunoglobulin A expression, converge to shape compositional features of the gut microbiome in an advanced intercross population of mice. Genome Biol. 2014;15(12):552.

42. Rausch P, Basic M, Batra A, Bischoff SC, Blaut M, Clavel T, Gläsner J, Gopalakrishnan S, Grassl GA, Günther C, Haller D, Hirose M, Ibrahim S, Loh 
G, Mattner J, Nagel S, Pabst O, Schmidt F, Siegmund B, Strowig T, Volynets V, Wirtz S, Zeissig S, Zeissig Y, Bleich A, Baines JF. Analysis of factors contributing to variation in the C57BL/6J fecal microbiota across German animal facilities. Int J Med Microbiol. 2016;306(5):343-55.

43. Gao Z, Tseng CH, Strober BE, Pei Z, Blaser MJ. Substantial alterations of the cutaneous bacterial biota in psoriatic lesions. PLoS One. 2008:3(7):e2719.

44. Kong HH, Oh J, Deming C, Conlan S, Grice EA, Beatson MA, Nomicos E, Polley EC, Komarow HD, NISC Comparative Sequence Program, Murray PR, Turner ML, Segre JA. Temporal shifts in the skin microbiome associated with disease flares and treatment in children with atopic dermatitis. Genome Res. 2012;22(5):850-9.

45. Campbell BJ, Yu L, Heidelberg JF, Kirchman DL. Activity of abundant and rare bacteria in a coastal ocean. Proc Natl Acad Sci U S A. 2011;108(31): 12776-81.

46. Panattoni M, Sanvito F, Basso V, Doglioni C, Casorati G, Montini E, Bender JR, Mondino A, Pardi R. Targeted inactivation of the COP9 signalosome impairs multiple stages of T cell development. J Exp Med. 2008;205(2):465-77.

47. Fyhrquist N, Ruokolainen L, Suomalainen A, Lehtimäki S, Veckman V, Vendelin J, Karisola P, Lehto M, Savinko T, Jarva H, Kosunen TU, Corander J, Auvinen P, Paulin L, von Hertzen L, Laatikainen T, Mäkelä M, Haahtela T, Greco D, Hanski I, Alenius H. Acinetobacter species in the skin microbiota protect against allergic sensitization and inflammation. J Allergy Clin Immunol. 2014;134(6):1301-1309.e11.

48. Pan Y, Yang H, Claret FX. Emerging roles of Jab1/CSN5 in DNA damage response, DNA repair, and cancer. Cancer Biol Ther. 2014:15(3):256-62.

49. Kouvaraki MA, Rassidakis GZ, Tian L, Kumar R, Kittas C, Claret FX. Jun activation domain-binding protein 1 expression in breast cancer inversely correlates with the cell cycle inhibitor p27(Kip1). Cancer Res. 2003;63(11):2977-81.

50. Dong Y, Sui L, Watanabe Y, Yamaguchi F, Hatano N, Tokuda M. Prognostic significance of Jab1 expression in laryngeal squamous cell carcinomas. Clin Cancer Res. 2005;1 1(1):259-66.

51. Harada K, Kawashima Y, Yoshida H, Sato M. High expression of Jun activation domain-binding protein 1 (Jab1) is a strong prognostic marker in oral squamous cell carcinoma patients treated by UFT in combination with radiation. Anticancer Res. 2006;26(2B):1615-9.

52. Ivan D, Diwan AH, Esteva FJ, Prieto VG. Expression of cell cycle inhibitor p27 $7^{\text {kip } 1}$ and its inactivator Jab1 in melanocytic lesions. Mod Pathol. 2004;17:811-8.

53. Attene-Ramos MS, Wagner ED, Plewa MJ, Gaskins HR. Evidence that hydrogen sulfide is a genotoxic agent. Mol Cancer Res. 2006;4:9-14.

54. Gibson GR, Cummings JH, Macfarlane GT. Growth and activities of sulphatereducing bacteria in gut contents of healthy subjects and patients with ulcerative colitis. FEMS Microbiol Lett. 1991;86:103-11.

55. Pitcher MCL, Beatty ER, Gibson GR, Cummings JH. Incidence and activities of sulphate-reducing bacteria in patients with ulcerative colitis. Gut. 1995;36:A63.

56. Christl SU, Eisner HD, Dusel G, Kasper H, Scheppach W. Antagonistic effects of sulfide and butyrate on proliferation of colonic mucosa: a potential role for these agents in the pathogenesis of ulcerative colitis. Dig Dis Sci. 1996;41:2477-81.

57. Kutz JL, Greaney JL, Santhanam L, Alexander LM. Evidence for a functional vasodilatatory role for hydrogen sulphide in the human cutaneous microvasculature. J Physiol. 2015;593(9):2121-9.

58. Wang Z, Yin X, Gao L, Feng S, Song K, Li L, Lu Y, Shen H. The protective effect of hydrogen sulfide on systemic sclerosis associated skin and lung fibrosis in mice model. Springerplus. 2016;5(1):1084.

59. Vervoort SJ, van Boxtel R, Coffer PJ. The role of SRY-related HMG box transcription factor 4 (SOX4) in tumorigenesis and metastasis: friend or foe? Oncogene. 2013;32(29):3397-409.

60. Foronda M, Martínez P, Schoeftner S, Gómez-López G, Schneider R, Flores JM Pisano DG, Blasco MA. Sox4 links tumor suppression to accelerated aging in mice by modulating stem cell activation. Cell Rep. 2014;8(2):487-500.

61. Sagar S, Esau L, Holtermann K, Hikmawan T, Zhang G, Stingl U, Bajic VB, Kaur M. Induction of apoptosis in cancer cell lines by the Red Sea brine pool bacterial extracts. BMC Complement Altern Med. 2013;13:344.

62. Edgar RC. Search and clustering orders of magnitude faster than BLAST. Bioinformatics. 2010;26(19):2460-1.

63. Edgar RC, Flyvbjerg H. Error filtering, pair assembly, and error correction for next generation sequencing reads. Bioinformatics. 2015;31(21):3476-82.

64. Edgar RC, Haas BJ, Clemente JC, Quince C, Knight R. UCHIME improves sensitivity and speed of chimera detection. Bioinformatics. 2011;27(16): 2194-200.

65. Pruesse E, Quast C, Knittel K, Fuchs BM, Ludwig WG, Peplies J, Glöckner FO. SILVA: a comprehensive online resource for quality checked and aligned ribosomal RNA sequence data compatible with ARB. Nucleic Acids Res. 2007:35:7188-96.

66. Wang Q, Garrity GM, Tiedje JM, Cole JR. Naive Bayesian classifier for rapid assignment of rRNA sequences into the new bacterial taxonomy. Appl Environ Microbiol. 2007;73(16):5261-7.

67. Schloss PD, Westcott SL, Ryabin T, Hall JR, Hartmann M, Hollister EB, Lesniewski RA, Oakley BB, Parks DH, Robinson CJ, Sahl JW, Stres B, Thallinger GG, Van Horn DJ, Weber CF. Introducing mothur: open-source, platformindependent, community-supported software for describing and comparing microbial communities. Appl Environ Microbiol. 2009;75(23):7537-41.

68. Schloss PD, Gevers D, Westcott SL. Reducing the effects of PCR amplification and sequencing artifacts on $16 \mathrm{~S}$ rRNA-based studies. PLoS One. 2011;6(12):e27310.

69. Purcell S, Neale B, Todd-Brown K, Thomas L, Ferreira MAR, Bender D, Maller J, Sklar P, de Bakker PIW, Daly MJ, Sham PC. PLINK: a tool set for wholegenome association and population-based linkage analyses. Am J Hum Genet. 2007;81(3):559-75.

70. Mott R, Flint J. Simultaneous detection and fine-mapping of quantitative trait loci in mice using heterogenous stocks. Genetics. 2002;160:1609-18.

71. R Core Team. R: a language and environment for statistical computing. Vienna: R Foundation for Statistical Computing; 2014. http://www.R-project.org/.

72. Bates $\mathrm{D}$, Maechler M, Bolker B, Walker S. Fitting linear mixed-effects models using Ime4. J Stat Softw. 2015;67(1):1-48.

73. Nakagawa S, Schielzeth H. A general and simple method for obtaining $R^{2}$ from generalized linear mixed-effects models. Methods Ecol Evol. 2012;4(2):133-42.

74. Barton K. MuMIn: multi-model inference, R package. 2015.

75. Cheng R, Abney M, Palmer AA, Skol AD. QTLRel: an R package for genomewide association studies in which relatedness is a concern. BMC Genet. 2011;12:66.

76. Gatti DM, Svenson KL, Shabalin A, Wu L-Y, Valdar W, Simecek P, Goodwin N, Cheng R, Pomp D, Palmer A, Chesler EJ, Broman KW, Churchill GA. Quantitative trait locus mapping methods for diversity outbred mice. G3. 2014:4:1623-33.

77. Svenson KL, Gatti DM, Valdar W, Welsh CE, Cheng R, Chesler EJ, Palmer AA, McMillan L, Churchill GA. High-resolution genetic mapping using the mouse diversity outbred population. Genetics. 2012;190:437-47.

78. Churchill GA, Doerge RW. Empirical threshold values for quantitative trait mapping. Genetics. 1994;138(3):963-71.

79. Oksanen J, Blanchet FG, Kindt R, Legendre P, Minchin PR O'Hara RB, Simpson GL, Solymos P, Stevens MHH, Wagner H. Vegan: Community Ecology Package. 2015.

80. Harrell Jr FE. With contributions from Charles Dupont and many others. Hmisc: Harrell miscellaneous, R package. 2015.

81. Wei T. Corrplot: visualization of a correlation matrix, R package. 2013.

82. Yang YW, Chen MK, Yang BY, Huang XJ, Zhang XR, He LQ, Zhang J, Hua ZC. Use of 165 rRNA gene-targeted group-specific primers for real-time PCR analysis of predominant bacteria in mouse feces. Appl Environ Microbiol. 2015;81(19):6749-56.

83. Hermann-Bank ML, Skovgaard K, Stockmarr A, Larsen N, Mølbak L. The gut microbiotassay: a high-throughput $\mathrm{QPCR}$ approach combinable with next generation sequencing to study gut microbial diversity. BMC Genomics. 2013:14:788.

84. Guo X, Xia X, Tang R, Wang K. Real-time PCR quantification of the predominant bacterial divisions in the distal gut of Meishan and Landrace pigs. Anaerobe. 2008;14(4):224-8.

85. Chen EY, Tan CM, Kou Y, Duan Q, Wang Z, Meirelles GV, Clark NR, Ma'ayan A. Enrichr: interactive and collaborative HTML5 gene list enrichment analysis tool. BMC Bioinformatics. 2013;128:14. 